\title{
The Arctic DP Research Project: Effective Stationkeeping in Ice
}

\author{
Roger Skjetne ${ }^{1}$ Lars Imsland ${ }^{2}$ Sveinung Løset ${ }^{3}$
}

\author{
${ }^{1}$ Department of Marine Technology, Norwegian University of Science and Technology, \\ NO-7491 Trondheim, Norway. E-mail: roger.skjetne@ntnu.no \\ ${ }^{2}$ Department of Engineering Cybernetics, Norwegian University of Science and Technology, \\ NO-7491 Trondheim, Norway. E-mail: lars.imsland@ntnu.no \\ ${ }^{3}$ Department of Civil and Transport Engineering, Norwegian University of Science and Technology, \\ NO-7491 Trondheim, Norway. E-mail: sveinung.loset@ntnu.no
}

\begin{abstract}
Stress on the environment from a potentially growing energy use is set to rise. Without doubt the energy resources in Arctic regions will be developed. An important goal will be to exploit the resources offered by for instance the Barents Sea as a new European energy province, and to do this in accordance with the principles of sustainable development that have successfully been used e.g. in the North Sea.

The special edition of MIC on Arctic DP presents a set of articles that summarize to an extent the activities of the research project "Arctic DP: Safe and green dynamic positioning operations of offshore vessels in an Arctic environment". This project was awarded in 2010 by the Research Council of Norway (RCN) as a competence-building project (KMB project) to NTNU and its partners Kongsberg Maritime, DNV GL, and Statoil. The objective was to target some of the challenges related to safe Arctic offshore operations by dynamic positioning. In this first article of the Arctic DP special edition we discuss the background for and establishment of the project, its planning and execution, and project closure. An overview is given for the scientific and engineering research performed in the project, with an account of what we have considered as Effective stationkeeping in ice by dynamic positioning. The corresponding research activities conducted under this main theme is summarized.
\end{abstract}

Keywords: Arctic oil and gas; Arctic offshore operations; Dynamic Positioning; Ice Management; Ice surveillance; Icebreakers.

\section{Introduction}

A forecast by the United States Geological Survey (Gautier et al., 2009) states that approximately 30\% of the world's undiscovered gas and $13 \%$ of the undiscovered oil may be located in the Arctic, as shown in Figure 1. The fact that easily accessible hydrocarbon resources are getting scarcer has been an incentive for offshore technology and operations to approach Arctic regions. Exploration and exploitation of Arctic energy resources, however, pose significant challenges for industry, especially in the assessment and management of risks along the whole production chain, avoidance of disruptions arising from potentially manageable accidents, and the need to minimize costs arising from adverse environmental impacts.

A few pioneering stationkeeping operations in seaice have initiated this development. One example was reported by Keinonen et al. (2000) on the first ever dynamic positioning (DP) operation in ice, offshore 


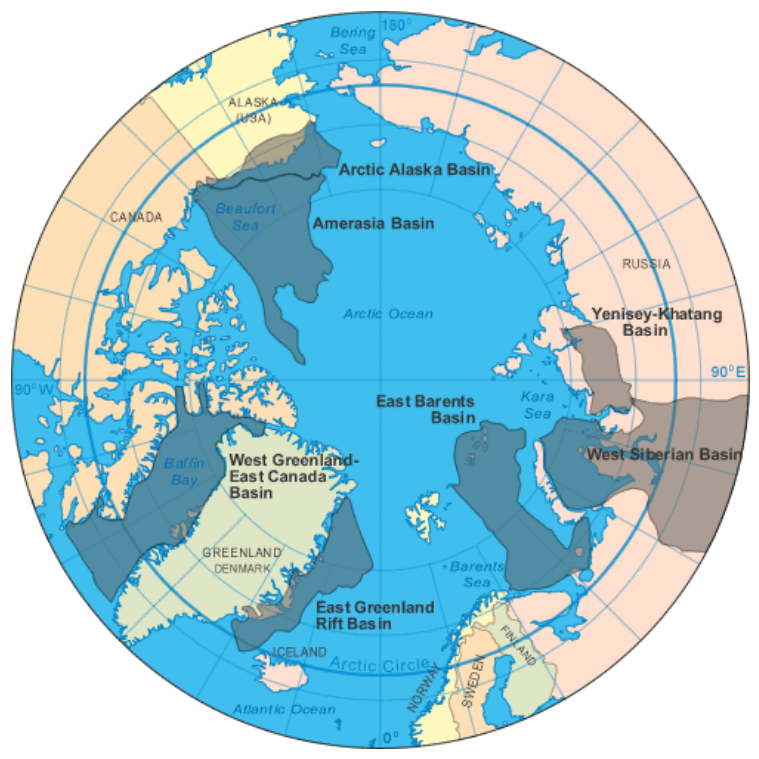

Figure 1: Arctic Oil and Natural Gas Provinces Map. Courtesy: Geology.com (2014)

Sakhalin, Russia, between May and June, 1999. This operation was performed to carry out compression diving by a DP vessel, CSO Constructor, having ice class B. It was supported by two icebreakers to manage the level ice into ice floes small enough for the CSO Constructor to handle its DP diving operation.

Another exemple frequently referred to in the Arctic DP project was reported by Moran et al. (2006) on the experiences from the Arctic Coring Expedition (ACEX) in 2004, a challenging Arctic offshore operation that successfully drilled and recovered deeply buried sediments northwest of Franz Josef Land in the Arctic ocean, an area covered by more than $90 \%$ of permanent sea-ice, including level ice, ridges, and large ice floes. As shown in Figure 2, this drilling campaign consisted of three vessels, the Russian nuclear powered icebreaker Sovetskiy Soyuz that would break the drifting incoming level ice into large ice floes, the Swedish diesel-electric icebreaker Oden that would break the large ice floes into smaller pieces, and the Swedish diesel-electric icebreaker Vidar Viking that for this expedition was converted to a DP capable drillship. Under the dense ice conditions encountered, the Vidar Viking was not successful in carrying out automatic DP. Instead, a manual DP procedure was developed using the joystick. This involved:

- an accurate prediction of the ice drift using a marine radar,

- a helicopter for ice surveillance, that was used to place GPS trackers on large ice floes,

- a vessel heading set to exactly counter the ice drift direction, and
- a repetitive longitudinal (surge) motion up- and downstream $\pm 20 \mathrm{~m}$ relative to the drillsite position in order to additionally use the ship's inertia to handle large pieces of ice.

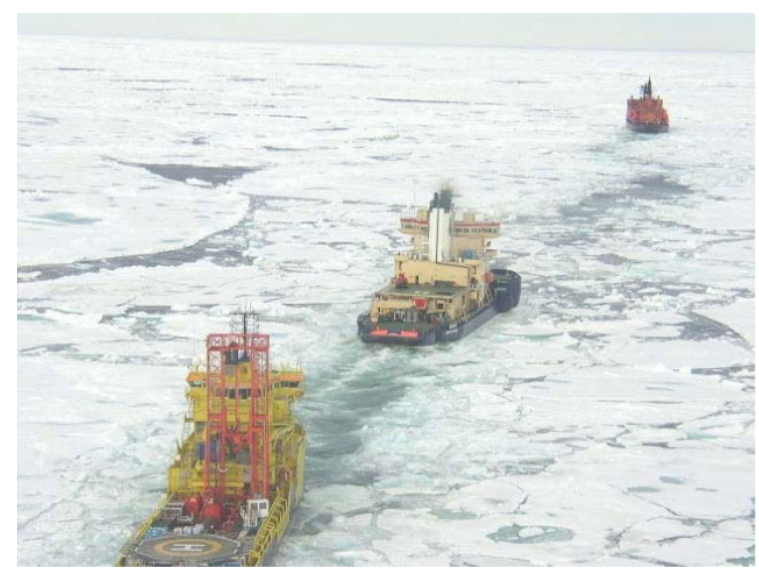

Figure 2: Arctic Coring Expedition (2004) with Vidar Viking, Oden, and Sovetskiy Soyuz from near to far. Courtesy: Moran et al. (2006)

\subsection{Project objectives, vision, and goal}

The aforementioned pioneering expeditions and several other examples have shown that operations in Arctic offshore fields pose new challenges related to sustainable development in a vulnerable ecosystem. There are substantial gaps in knowledge related to performance of vessels in sea-ice, methods for risk mitigation by an ice management system, emergency preparedness and response, and corresponding maturity of relevant technology to be used in an Arctic climate. It was therefore an expressed need to strengthen the competences of the Norwegian maritime industry in Arctic offshore operations with special focus on dynamic positioning (DP). The following project objectives were thus defined:

- To develop competence and knowledge necessary for the system supplier industry to improve existing technology and/or to develop new technology for DP of offshore vessels in the Arctic. Particular attention should be paid to the DP system when this is influenced by various conditions of sea-ice.

- To improve competence and knowledge necessary for class societies to implement rules, guidelines, and instructions for verification and validation of the technical systems and operational procedures for safe DP operations in an ecologically sensitive Arctic environment.

- To increase the knowledge and awareness of end clients (oil companies and other stakeholders) to 


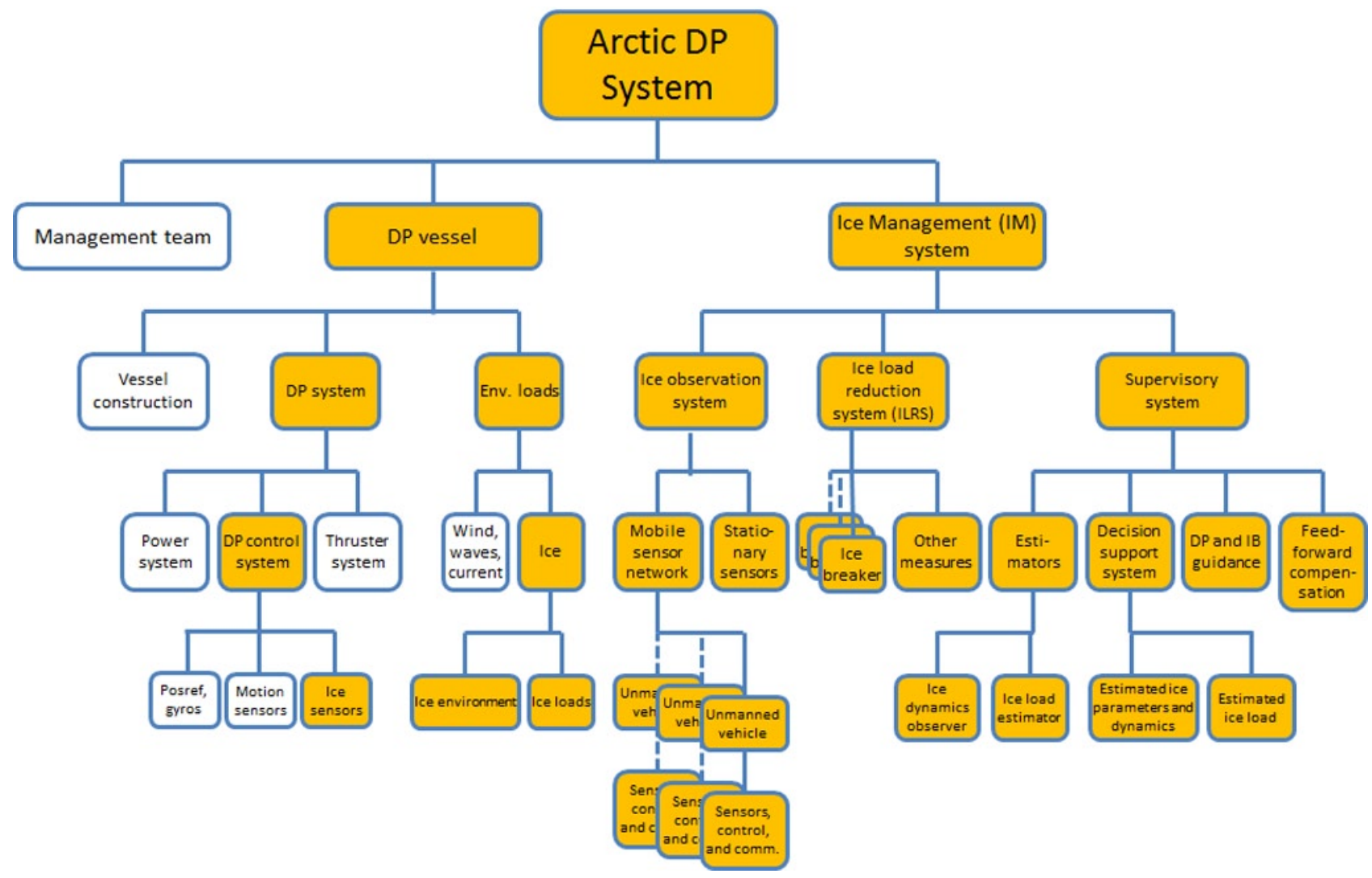

Figure 3: Arctic DP work breakdown structure.

critical issues regarding the technology and procedures for DP operations in relation to exploration drilling, anchor handling, well intervention, hydrocarbon production, supply services, etc.

Based on these objectives, a vision was proposed:

The vision of the Arctic DP project is for Norwegian industry to attain world leading competence and knowledge of DP system technology and operation developed for safe and environmentally robust DP operations of offshore vessels in Arctic environments.

This was further translated into the main goal:

To supply the industry with highly qualified personnel within the field of DP control systems technology developed for acceptable operations of DP vessels in Arctic environments.

\subsection{Work breakdown}

A work breakdown was done in the early project phase to determine the focus of the research and divide the project into suitable work packages. This is given by the work breakdown structure (WBS) in Figure 3.

Primarily, the research project intended to investigate the control problem of understanding better the vessel-ice interaction forces and proposing new control mechanisms for compensating these ice loads. However, it was found through the WBS from a control engineering perspective, that significant effort also should go into the ice surveillance problem. More measurements with better spatial and temporal resolution of sea-ice parameters is generally needed to ensure the required safety level for managing the drifting sea-ice by the icebreakers and for compensating the ice loads by the protected DP vessel.

Better ice monitoring also has an online perspective, if such superior information of sea-ice parameters is needed in a real-time perspective to plan the operation better and to facilitate feedforward structures for faster responses to rapid changes in the ice field. Based on this, another research perspective was identified as the ability to better simulate and predict the variations in the ice field and the corresponding responses of different vessels of the operation. 


\subsubsection{Work packages and research tasks}

Based on the WBS, the following scientific work packages and assignment of research tasks were specified:

- WP2: DP control system redesign.

- PhD study 1: Guidance and control of a DP vessel to handle feasible ice loads. Study conducted by $\mathrm{PhD}$ cand. Øivind K. Kjerstad.

- Additional research task: Fault-tolerant control for Arctic DP. Study conducted by PhD cand. Bo Zhao.

- WP3: Autonomous ice observation system.

- PhD study 2: Autonomous aerial ice observation system. Study conducted by $\mathrm{PhD}$ Joakim Haugen.

- PhD study 3: Autonomous underwater ice observation system. Study conducted by $\mathrm{PhD}$ cand. Ulrik Jørgensen.

- PhD study 5: Image and sensory data processing for ice observation. Study conducted by $\mathrm{PhD}$ cand. Qin Zhang.

- WP4: Ice Management ice load reduction.

- PhD study 4: Ice loads modelling and integrated simulations of floating structures in ice. Study conducted by $\mathrm{PhD}$ cand. Ivan Metrikin.

- Additional research task: Verification risk and verification management for Arctic DP operations. Study conducted by researcher Stian Ruud.

Two post-doc positions were also assigned in the project. These aided in project administration, supported research by the $\mathrm{PhD}$ candidates, and performed own research on a relevant topic. The employed candidates were:

- Postdoctoral fellowship 1: Francesco Scibilia, employed 2010-2012, with own research on control engineering applied to physical ice management.

- Postdoctoral fellowship 2: Biao Su, employed 2012-2014, with own research on numerical simulation of maneuverability of ice-going ships.

The project has been managed by Professor Roger Skjetne at the Department of Marine Technology, NTNU, with scientific partners Professor Sveinung Løset at the Department of Civil and Transport Engineering, and Professor Lars Imsland at the Department of Engineering Cybernetics. The contacts from the industry partners have been Nils Albert Jenssen (Kongsberg Maritime), Stian Ruud (DNV GL), and Glenn-Ole Kaasa and Arne Gürtner (Statoil).

\subsection{Project closure}

The project officially ends on December $31^{\text {st }} 2014$. During the 5-year period of the project, it has employed $5 \mathrm{PhD}$ students, 2 post-doc researchers, and 2 short-term research positions.

The project gave a special session on "Challenges in the Arctic" on the Norwegian conference Servomøtet (Norsk Forening for Automatisering, 2014); cf. Figure 4 .

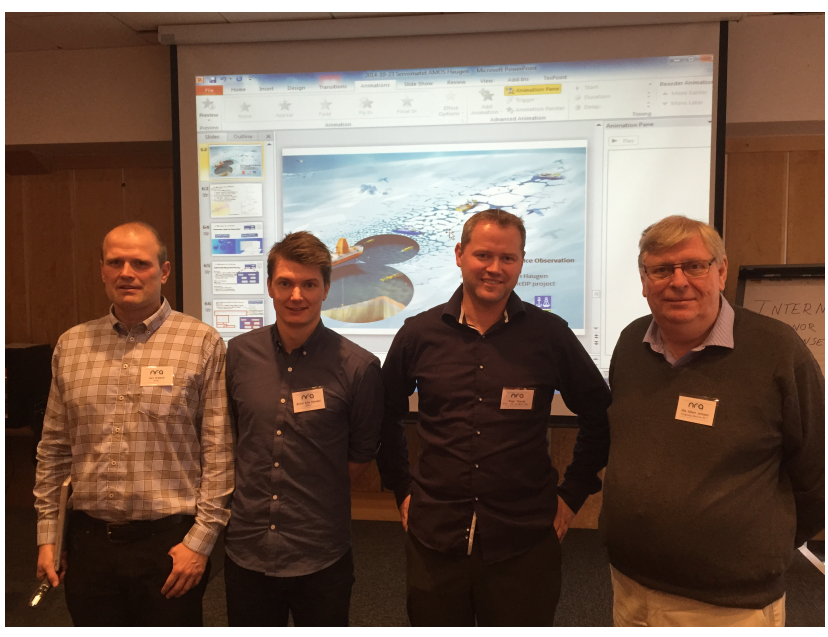

Figure 4: Participation Servomøtet 2014 at Kongsberg, Norway. From left: Lars Imsland, Øivind K. Kjerstad, Roger Skjetne, and Nils A. Jenssen.

This special edition in MIC makes out the closing scientific report for the project.

\section{Effective stationkeeping in ice}

A conventional DP control system is designed to compensate environmental loads from waves, wind, and ocean currents:

- The ocean currents and the $2^{\text {nd }}$ order waveinduced loads are considered to change slowly such that the integral action in the PID-type control law is synthesized to compensate this. In the DP Operator Station (DPOS), this integral action is presented as an estimated current with a speed and direction. However, since this integral action also compensates wave drift forces, unmodeled dynamics in the thruster system, and other discrepancies, it is typically referred to as the "DP current" not to be mistaken for the real ocean current.

- The $1^{\text {st }}$ order wave-induced loads produce oscillatory motions with zero-mean drift on the vessel. Thus, the DP control law is implemented with a 
"wave-filter" to avoid unnecessary wave frequency (WF) oscillations in the control loop to reduce wear and tear of the propulsive devices. The $2^{\text {nd }}$ order wave-induced loads (the wave-drift forces) are, as mentioned above, compensated by the integral action as slowly varying forces.

- The wind loads are compensated by a feedforward control term based on wind sensors. These measure the speed and direction of the incoming wind on the vessel, and a static formula is used to estimate the corresponding wind force and moment on the vessel based on wind coefficients and projected areas.

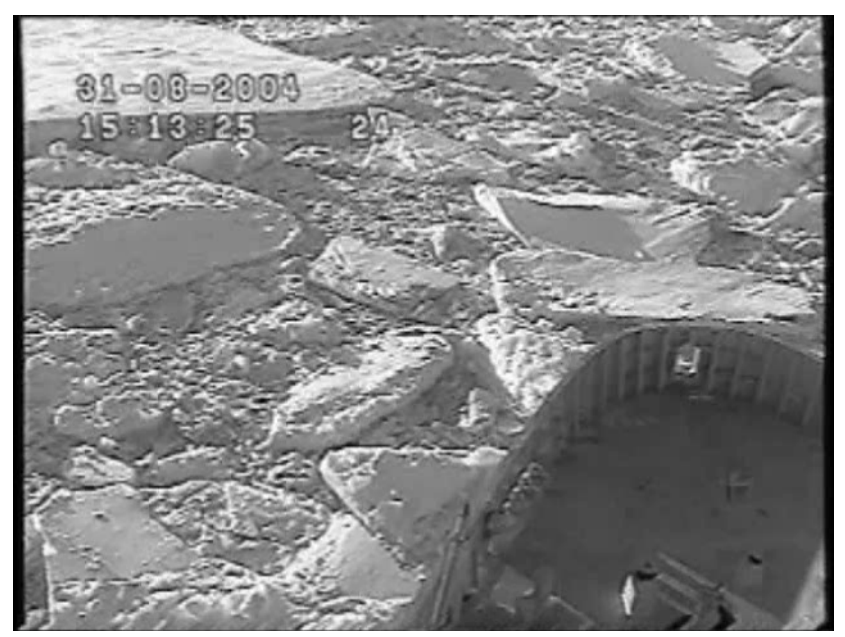

Figure 5: Bridge camera picture of surrounding ice condition of Icebreaker Vidar Viking during DP operation in the ACEX expedition on August 31, 2004. Courtesy: ACAC Inc.

As explicitly visualized in Figure 5, DP in ice introduces a new environmental load from the drifting seaice. With an ice management system, icebreakers will break the incoming level ice into ice floes. These ice floes behave as a large contact network of rigid bodies that drift against, hit, and push the vessel. This contact network can build up and break down rapidly. When a large accumulation of ice floes is built up in the drifting ice field, this gives an equivalent increased body and mass that the DP control system will try to position against the ocean current drag forces. Obviously, more thrust force is needed to achieve this.

The resulting characteristics of the global ice load on the DP vessel due to such large build-up and breakdown of forces, is different from the conventional openwater loads. The sea-ice loads can become significantly larger in mean value, experience large and rapid fluctuations, and generate seemingly instant event-loads.
There exist no good combination of a characteristic load model and a sensor solution to measure and estimate this load on the vessel.

The Arctic DP project perspective of these challenges (cf. Figure 6) have been to consider effective stationkeeping operations under three main themes:

- Effective ship design for stationkeeping operations in sea-ice.

- Effective Ice Management system.

- Effective strategies for the DP control system to compensate ice loads.

We discuss these topics next, in terms of some results from the Arctic DP project.

\subsection{Effective ship design for operation in ice}

Until now, only fixed offshore structures, gravel islands, and caissons have been used under Arctic conditions as permanent offshore oil and gas production facilities. In the coming decades, however, more developments are expected in deeper Arctic waters, such as offshore Greenland and in the Russian Arctic. In these deeper waters floating structures are preferred concepts.

In a ship-shaped vessel design for DP operations in ice, one must consider:

- Efficient hull design for stationkeeping in ice contra open water performance.

- Thruster system - number, types, and locations of thrusters, their performance in ice, and special modes such as using thrusters to clear ice.

- Design of moonpools, cranes, deck areas, work areas, etc.

- Safety and emergency functions related to detection and handling of icebergs and ice ridges, detection of changes in ice drift direction, changes in Arctic environmental conditions, and so on.

The operational profile of the vessel is particularly important. Should the vessel be purpose-built to operate all-time all-year in sea-ice condition, or should it be built for summer season? Should it have both ice and open-water capabilities? Should the vessel be designed with transit performance in open water as well as ice-going capabilities?

The Arctic DP project has not targeted such design questions. Instead collaboration agreements was established with two partner projects:

- CIV Arctic: Construction and intervention vessels for Arctic oil and gas. RCN KMB project no. 188913.

- DYPIC: Dynamic Positioning in Ice Covered Waters. MARTEC ERA-NET and RCN project no. 196897. 


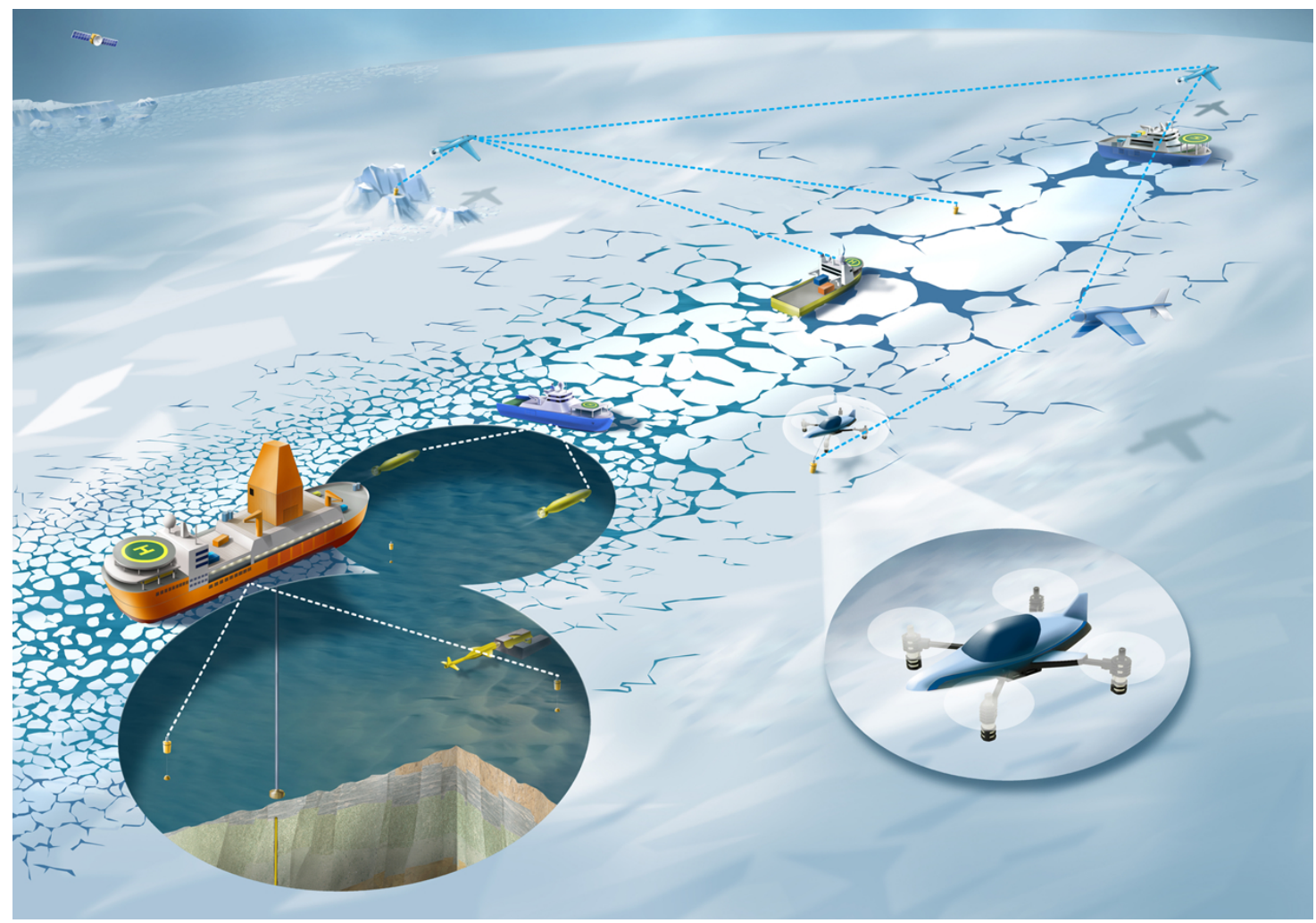

Figure 6: Foreseen Arctic DP operation with a sophisticated Ice Management System. Three icebreakers manage the upstream incoming ice to reduce loads on the protected vessel, which here is an Arctic drillship. A future-oriented autonomous ice surveillance system is illustrated to measure and communicate ice and metocen information from various stationary sensors and a satellite, aerial drones, and underwater vehicles as mobile sensor platforms. Copyright: NTNU, Illustration: Bjarne Stenberg

In the DYPIC project two model ships especially designed for Arctic operations have been tested in freefloating DP tests in model ice at the Hamburg Ship Model Basin (HSVA) (Jenssen et al., 2012), an Arctic Drillship and a Polar Research Vessel. Particular attention was paid in our project to the Arctic Drillship shown in Figure 7 in the development of a numerical ice tank; see e.g. (Metrikin et al., 2013) and (Metrikin and Løset, 2013). We will return to this development later.

In the CIV Arctic project (Berg, 2012) the design of a construction and intervention vessel was considered for intervention tasks conducted in seasonal drift ice conditions. The vessel was specified with a shore base in Hammerfest, Norway, and operation at three offshore fields as shown in Figure 8:

1. Barents Sea South (Goliat field), $50 \mathrm{~km}$ off the coast and $3 \mathrm{~h}$ transit time,

2. Barents Sea North (Olga field east of Spitsbergen) along a northern route with $29 \mathrm{~h}$ transit time, and

3. Haltenbanken along a southern route with $32 \mathrm{~h}$ transit time.
Su et al. (2014) has conducted a numerical analysis of the ice-breaking capability and maneuverability for the CIV Arctic vessel. This was based on a numerical ice-hull interaction model, for which the simulated icebreaking patterns, $\mathrm{h}-\mathrm{v}$ curves, and turning circles in different modes of operation were discussed and partly compared with corresponding ice model tests.

In the work by $\mathrm{Su}$ et al. (2013) this also included a DP-Ice Capability Plot. To recapitulate what this is, an open water DP Capability Plot is produced for a DP system to show the limiting environmental conditions in which the DP vessel is able to maintain its position and heading for various thruster configurations, including the defined worst-case failure configuration. For a conventional DP Capability Plot there are standardized formulas relating wind, wave, and current parameters to the resulting loads acting on the vessel. For a given thruster configuration, thrust allocation is then used to verify if a set of environmental loads are within the thrust capability of the vessel in stationary conditions. Finding the limiting condition for all angles around the vessel, one can finally plot an envelope, typ- 


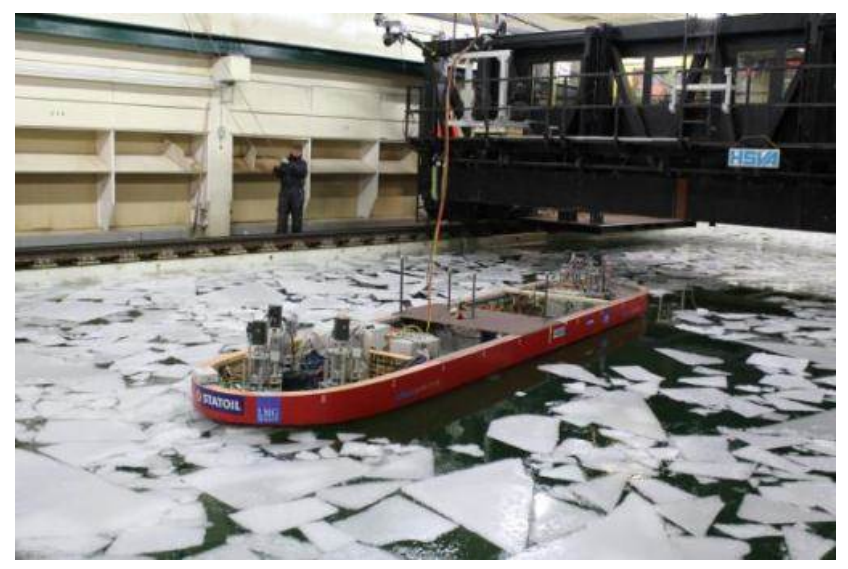

Figure 7: Statoil/LMG designed Arctic Drillship during free-floating DP model testing in the ice tank of HSVA. Courtesy: HSVA

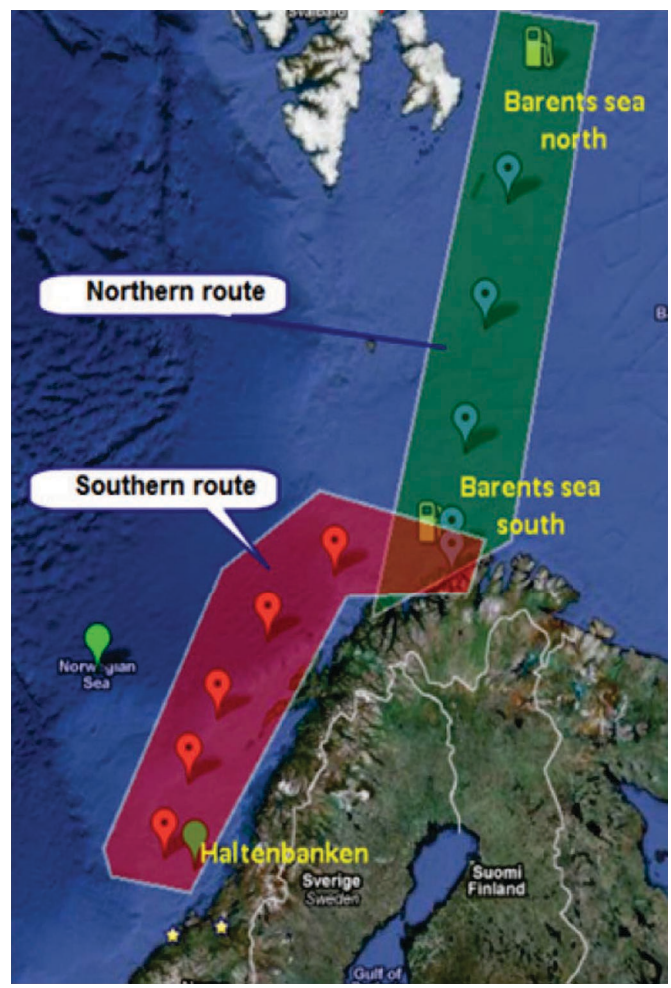

Figure 8: The CIV Arctic vessel was considered with a shore base at Hammerfest, and operations at Barents Sea North (Olga field), Barents Sea South (Goliat field), and Haltenbanken. Courtesy: Berg et al. (2011)

ically parameterized by wind speed, that corresponds to the DP Capability Plot.

For DP in ice we want to do this also for ice forces. However, we do not have static formulas relating specific ice parameters to a force and moment on the ves- sel. What we have, however, are numerical simulation tools. Hence, for a given set of ice parameters, we can alternatively simulate that the ice drifts and interacts with the vessel at a specific direction with a given speed, or conversely that the vessel moves at constant speed and heading through a stationary ice field.

This typically produces a force time series as shown in Figure 9, due to the randomness in the simulation parameters (ice density, breaking patterns, floe shapes, etc.), and not a single value as you get from the standard open water equations. We therefore need to select the ice force/moment value from such a time series to be further compared with the available vessel thrust. The average value is too small, the peak value typically lasts too shortly and does not have enough energy to move the vessel off position (and it is too conservative). Hence, a significant maximum value was defined as the average value of the $1 / 3$ largest peaks in the lowpass filtered time series (filtered to remove high-frequency "noise" before identifying the peaks).

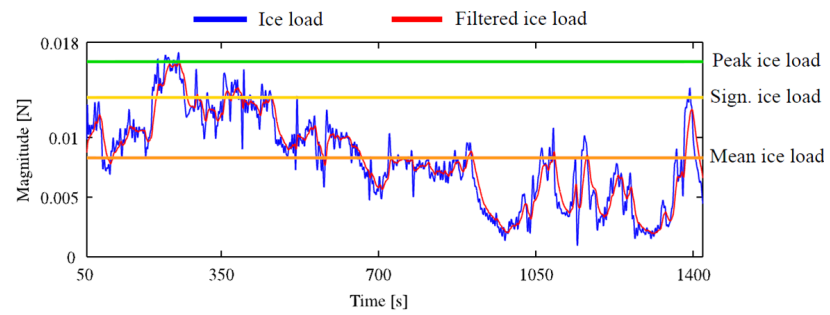

Figure 9: A simulated ice force series, with its average, peak, and significant maximum indicated. Courtesy: Kjerstad et al. (2013)

For each heading angle the vessel must then be simulated multiple times in different stationary speeds through the ice until a limiting condition is found, and then this procedure is repeated for all specified heading angles until a full envelope around the vessel is completed. Keeping the ice thickness constant and parameterizing the ice force by a varying drift speed gives one plot, while alternatively we can keep the drift speed constant and vary the ice thickness.

An example of the resulting plot with drift speed parameterization for the CIV Arctic vessel is shown in Figure 10. This illustrates the design of the CIV Arctic vessel, having a large ice breaking capability when the ice enters directly from bow or astern. If, however, the ice drift direction changes beyond the narrow sectors around these extremes, the icebreaking capability is drastically reduced. A detailed explanation for this is given by $\mathrm{Su}$ et al. (2013).

We make a note that since the applied simulator in this work is not directly applicable to slow speed simulations (DP simulations), the resulting DP-Ice Capabil- 

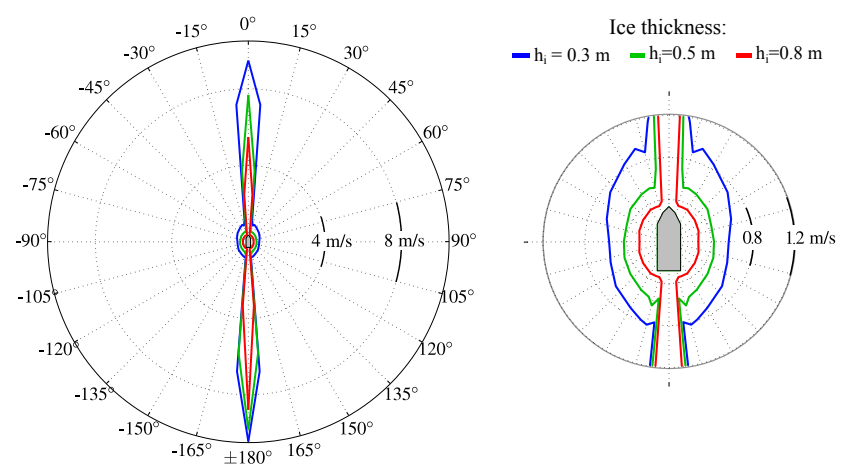

Figure 10: DP-Ice Capability Plot parameterized by varying ice drift speed for three different ice thicknesses. Courtesy: Su et al. (2013)

ity analysis is only illustrative. The thrust prioritizing allocation algorithm that was used for the DP-Ice Capability Plot analysis is presented in (Kjerstad et al., 2013) and (Skjetne and Kjerstad, 2013).

Another simulation-based procedure to generate a DP-Ice Capability plot, based on the DYPIC project, was presented by Kerkeni et al. (2013), where the influence of several ice parameters for such an analysis were extensively studied.

\subsection{Effective Ice Management}

According to Eik (2010), Ice Mangement is defined as "the sum of all activities where the objective is to reduce or avoid actions from any kind of ice features". A future-oriented ice management system is visualized in Figure 11.

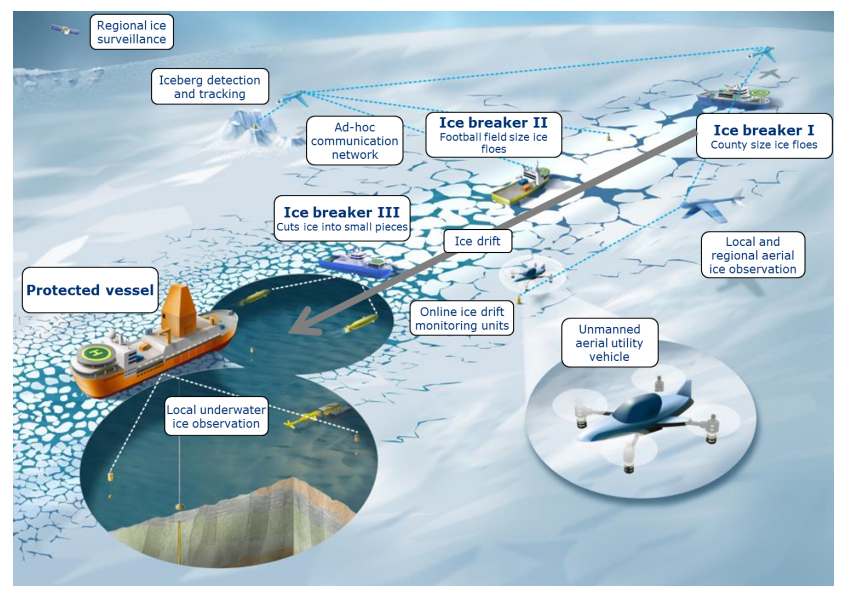

Figure 11: A foreseen Ice Management systemin the Arctic DP project, having a sophisticated Ice Surveillance system in addition to the icebreakers. Copyright: $N T N U$
We typically distinguish between sea-ice management and iceberg management. Generally, sea-ice management includes:

- Sea-ice surveillance: Global parameters (ice concentration, floe-size distribution, etc.); Local parameters (ice geometry, ice age, density, salinity, etc.); Motion and sea-ice tracking (ice drift velocity field, ice floe positions); Severe feature detection (ridge and iceberg detection and tracking).

- Threat evaluation: Forecasting and threat assessment (using weather forecasting and numerical simulation tools).

- Physical ice management: Using icebreakers to manage the ice field.

- Procedures and training.

According to Figure 12, the main objective of sea-ice management is to reduce the probability of peak loads from sea-ice on an Arctic offshore structure. This will then ensure that the design loads in terms of the Ultimate Limit State (ULS) and Accidental Limit State (ALS) requirements, are fulfilled for the Arctic offshore structure without being overly conservative.

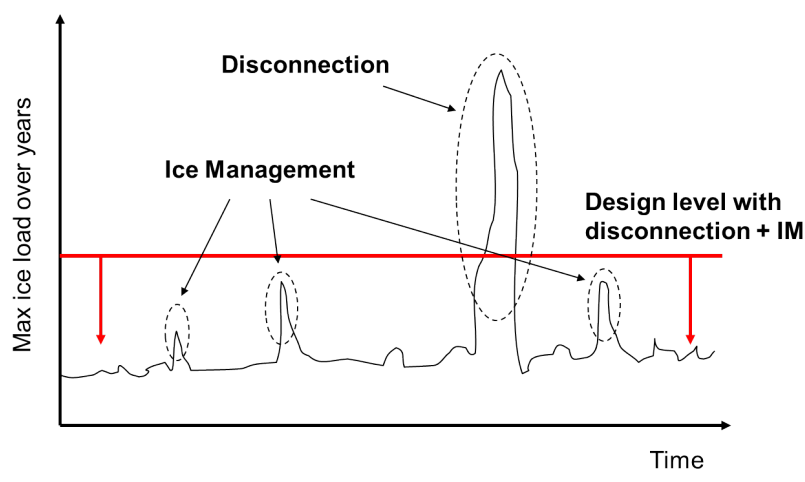

Figure 12: By Ice Management the ice load design level can be significantly reduced. The icebreakers will break the ice into ice floes smaller than a specified maximum size, giving an effective reduction of loads onto the protected vessel. Courtesy: Sveinung Løset

Iceberg management typically includes:

- Iceberg surveillance: Detection and tracking of icebergs.

- Threat evaluation: Forecasting and threat assessment (using weather forecasting and numerical simulation tools to predict iceberg trajectories).

- Iceberg handling: Single vessel towing, multivessel towing, propeller washing, water cannon, ramming, etc.

- Procedures and training. 


\subsubsection{Iceberg towing}

In the Arctic DP project we have done a study on Iceberg towing through two master theses (Sundland, 2013) and (Orsten, 2014). The latter thesis proposed a particularly interesting setup in a single vessel iceberg towing operation. The research objective was to safely tow an iceberg out of an offshore field along a specified straight-line path under the influence of ocean current. This involves two subproblems:

1. how to make the iceberg follow the path, and

2. how to limit the tow force to avoid the failure modes of towline rupture, towline slippage, and iceberg overturning.

To make the iceberg follow the path, an integral-Lineof-Sight (iLOS) algorithm (Børhaug et al., 2008) was used to online calculate the direction of the towline (or towing force vector) and consequently the towing position of the vessel. As reported by Orsten et al. (2014) and illustrated in Figure 13, the integral action in the iLOS algorithm will automatically compensate for the ocean current by estimating the appropriate towline direction.

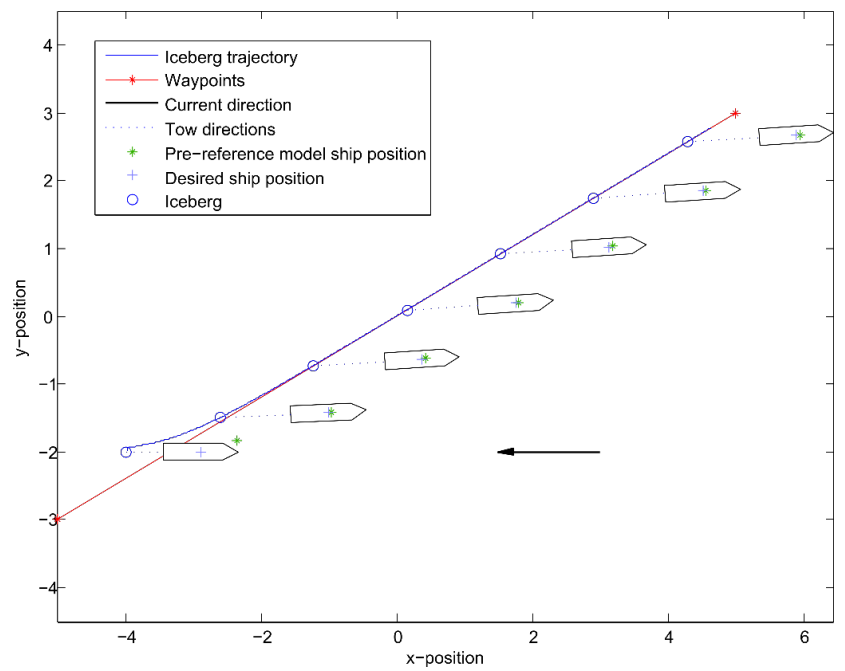

Figure 13: Iceberg towing in ocean current. The blue circles are the location of the iceberg at different instants of time. The iLOS algorithm ensures that a correct towline direction is enforced. Courtesy: Orsten et al. (2014)

To limit the towforce, an online reliability index algorithm (Berntsen, 2008) was embedded into the towing vessel speed control law. Based on continuous measurement of the towline tension, this continuously constrains the towing vessel speed such that the online calculated reliability index for the towline never drops below a threshold for which the mentioned failure modes are likely to occur.

\subsubsection{Sea-ice management}

The main focus in the Arctic DP project on ice management has been on sea-ice management. As illustrated in Figure 11, this consists of one or several icebreakers that break the upstream incoming ice into smaller and smaller ice floes, a stationkeeping vessel protected by the icebreakers, called the protected vessel, and several means to monitor the prevailing sea-ice and environmental condition and forecast its future development. An ice management team is supervising the overall ice management operation according to a set of procedures and an ice alert system designed for the specific offshore field and operation.

The required load reduction for the protected vessel by means of an ice management system is achieved by implementing measures for ice load reduction. Physically, icebreakers are used to work on the incoming ice to the offshore field and break it into ice floes. The required load reduction is typically specified by the operator of the protected vessel in terms of a maximum floe size that encounters the protected vessel after being managed. Hence, not only is it important to ensure capability to break the ice, but also to implement a surveillance system to monitor the sea-ice state both before and after the icereaking process.

The incoming level ice should be monitored and forecasted in terms of drift speed and direction, ice thickness, and detection of ice ridges and icebergs. Other parameters such as identification of ice age $\left(1^{\text {st }}\right.$ year or multi-year ice), ice density, salinity, etc., giving a measure of ice strength, is considered nice to have. The resulting broken ice should be monitored in terms of continuous measurements of ice concentration, floe size distribution, maximum floe size, ice thickness/geometry, ice field motion, etc.

In the Arctic DP project, studies have been conducted to consider some of these surveillance tasks:

- Underwater ice monitoring: How to continuously monitor and communicate the underwater ice topography over a spatial ice management domain by use of an underwater sensor platform such as an Autonomous Underwater Vehicle (AUV).

- Aerial ice monitoring: How to continuously monitor sea-ice parameters (e.g. ice concentration, floe size distribution, ice thickness, detection and tracking of severe ice features) by unmanned aerial vehicles equipped with appropriate sensors.

- Sea-ice image processing: How to apply image processing techniques on visual images of broken seaice to automatically extract important information such as ice concentration, floe size distribution, and individual floe sizes. 


\subsubsection{Underwater ice monitoring}

The following estimation problem have been considered. According to Figure 14 we have an AUV with an upward-looking MultiBeam EchoSounder (MBES) capable of measuring the topography in a small scanning area (yellow area in Figure 14). The operations area is divided into a grid of nodes, where we continuously estimate the draft of the drifting sea-ice in each node. We assume that the discretization length between each node is small enough so that the topography can be reconstructed with sufficient accuracy from this spatially sampled grid.

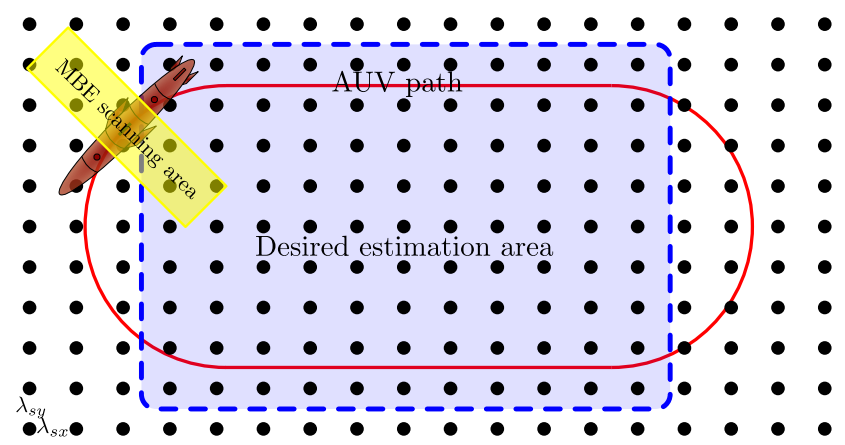

Figure 14: AUV scanning area of the drifting ice field, with is discretized into a grid of nodes. For each node the ice draft estimated and repeatedly measured by the circling AUV and an upward-looking MBES. Courtesy: Ulrik Jørgensen.

One challenge with online underwater monitoring is the ability to communicate the data to a surface-based operations center in real time. As illustrated in Figure 15, the proposed setup is to let the AUV measure the ice drafts by its MBES, automatically process the sensor data, and estimate the overall topography by its onboard CPU. This is based on a basis function allowing to represent the ice topography with a sufficiently low number of parameters. Then only these parameters need to be communicated online through the limited hydroacoustic channel. This ensures neccessary data compression at the same time as the topography can be recounstructed and visualized online in the operation center on the surface.

In the work by Jørgensen and Skjetne (2015), this problem was solved for the $2 \mathrm{D}$ case based on a truncated Fourier series as basis function. For a specific node located at displacement $\xi$ along the $x$-axis, the draft can be represented by the Fourier series

$$
\varphi(s)=\sum_{k=0}^{p}\left[a_{k} \cos k \kappa_{0}(s-\xi)+b_{k} \sin k \kappa_{0}(s-\xi)\right]
$$

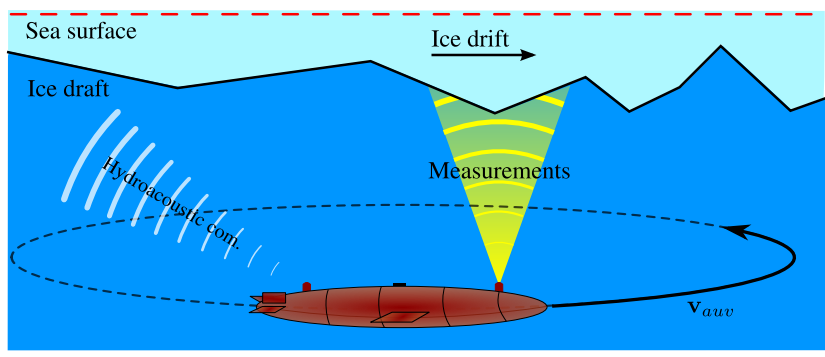

Figure 15: An AUV is measuring the ice draft along a specified path under the drifting sea-ice. Courtesy: Jørgensen and Skjetne (2015)

where $\kappa_{0}$ is the fundamental wave number and $s$ is the propagation variable with dynamics $\dot{s}=v$, making the ice field drift with constant velocity $v$. The coefficients $a_{k}, b_{k}, k=0,1, \ldots, p$ give the contribution of the $k^{\prime}$ th harmonic in this spatial signal. Stacking the coefficients into the vector $c \in \mathbb{R}^{m}, m=2 p+1$, and the sine and cosine functions in (1) into $h\left(\kappa_{0}, \xi, p ; s\right) \in \mathbb{R}^{m}$, then $\varphi(s)=h\left(\kappa_{0}, \xi, p ; s\right)^{\top} c$.

The draft at Node $i$ with position $x_{i}, i=1, \ldots, n$, in the defined area of surveillance, is $z_{i}=h\left(\kappa_{0}, x_{i}, p ; s\right)^{\top} c$, as shown in Figure 16.

Stacking the drafts into $z=\operatorname{col}\left(z_{1}, \ldots, z_{n}\right) \in \mathbb{R}^{n}$, then we get the vector relationship

$$
z=H(s)^{\top} c, \quad H: \mathbb{R} \rightarrow \mathbb{R}^{m \times n} .
$$

The matrix $H(s)$, with columns equal to the vectors $h\left(\kappa_{0}, x_{i}, p ; s\right)$ for all the nodes, has a special structure. This gives it some important properties as proved in (Jørgensen and Skjetne, 2015) and listed next.

If $H(s)$ is full row-rank, which can be ensured by

$$
\lambda_{s} \neq \frac{2 \pi}{k \kappa_{0}}, \quad \forall k \in\{1,2, \ldots, n-1\},
$$

then the following properties hold, independently of $s$ : P1: Let $s=\sigma-\theta$. Then $H(s)=R(\theta) H(\sigma)$ where $R(\theta) \in S O(m)$ is a rotation matrix with the property $\dot{R}=R(\theta) S(\dot{\theta})=S(\dot{\theta}) R(\theta)$ where $S(\dot{\theta})$ is skew-symmetric.

P2: The matrix norm $\|H(s)\|$ is constant and nonzero. Moreover, let $W=W^{\top}>0$ be a constant matrix. Then $H(s) W H(s)^{\top}$ is invertible and uniformly positive definite $\forall s \in \mathbb{R}$.

P3: Let $C(t)=\operatorname{diag}\left(c_{1}(t), c_{2}(t), \ldots, c_{n}(t)\right)$ define a sampling function, that is, if Node $i$ is currently measured, $c_{i}(t)=1$, if not measured, $c_{i}(t)=0$. Let $F(t, s):=H(s) C(t)$. If $\operatorname{rank}(C(t)) \geq m, \forall t$, then the properties P1-P2 hold also for $F(t, s)$, independently of $t$ and $s$.

A wave number spectral analysis of a typical ice topography for the field of interest, is used to determine the values of $\kappa_{0}, p$, and the sample distance $\lambda_{s}$. 


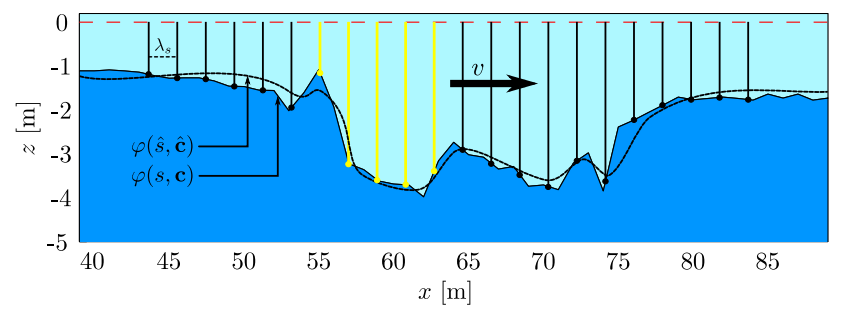

Figure 16: Ice topography drifting at speed $v$, and an estimation setup with nodes separated $\lambda_{s}[\mathrm{~m}]$ along the $x$-axis in which we measure and estimate the ice draft. The "real" topography $\varphi(s, c)$ and estimated topography $\varphi(\hat{s}, \hat{c})$ are also indicated. Courtesy: Jørgensen and Skjetne (2015)

Since both $s$ and $c$ in (2) are unknown, this gives an inconvenient nonlinear parameterization. However, letting $\hat{s}(t)$ be our estimate of $s(t)$ with $\dot{\hat{s}}=v$, then the displacement error

$$
\tilde{s}(t)=\hat{s}(t)-s(t)=v t+\hat{s}_{0}-v t-s_{0}=\tilde{s}_{0}
$$

is constant. According to property $\mathrm{P} 1$ above, $H(s)$ can be reparameterized according to $H(s)^{\top}=H(\hat{s}-\tilde{s})^{\top}=$ $H(\hat{s})^{\top} R(\tilde{s})^{\top}=H(\hat{s})^{\top} R\left(\tilde{s}_{0}\right)^{\top}$ where $R\left(\tilde{s}_{0}\right)$ becomes a constant matrix. This gives

$$
z=H(s)^{\top} c=H(\hat{s})^{\top} R\left(\tilde{s}_{0}\right)^{\top} c=H(\hat{s})^{\top} d .
$$

Only the new rotated coefficient vector $d:=R\left(\tilde{s}_{0}\right)^{\top} c$ is now unknown. Accordingly, a proposed setup to estimate the coefficients is by the observer model

$$
\begin{aligned}
& \dot{d}=0 \\
& y=C(t) z=F(t, \hat{s}(t))^{\top} d .
\end{aligned}
$$

Indeed, Jørgensen and Skjetne (2015) explored this setup and showed observability of the system. The paper proposed an observer setup and compared the efficiency of this with another setup based on B-splines as basis function. It can also be shown that the $2 \mathrm{D}$ setup and the structural properties of the $H(s)$-matrix are transferable to the $3 \mathrm{D}$ case. This is a work in progress leading towards the PhD thesis of Ulrik Jørgensen.

Further research activities on this subject is conducted by Petter Norgren on the topic "AUVs for subsurface monitoring of sea-ice and icebergs," using the REMUS 100 AUV and the facilities of the NTNU Applied Underwater Robotics Lab (AUR-Lab). This research and experimental activities through the AURLab are financed through the Norwegian Centre for Research-based Innovation (CRI) "Sustainable Arctic Marine and Coastal Technology" (SAMCoT) and the Norwegian Centre of Excellence $(\mathrm{CoE})$ in research
"Centre for Autonomous Marine Operations and Systems" (AMOS). More information about AUR-Lab can be found at http://www.ntnu.no/aur-lab.

\subsubsection{Aerial ice monitoring by drones}

The background for including surveillance with drones in the project, is the hypothesis that unmanned aerial vehicles (UAVs, or RPAS, remotely piloted aircraft systems, herein used synonymously) can be a cost-effective and safe ingredient in a system for ice observation. In this picture, RPAS can be seen both as a replacement for manned flights for ice observation, with obvious advantages in terms of cost and HSE, but also as an extension of other means for ice observation, for instance providing a larger coverage than marine radars, but with higher resolution than satellite imagery. Our belief is that aerial surveillance fills a gap in between other means of ice observation, cf. Figure 17. Haugen et al. (2011) provide further details on RPAS as a sensor platform.
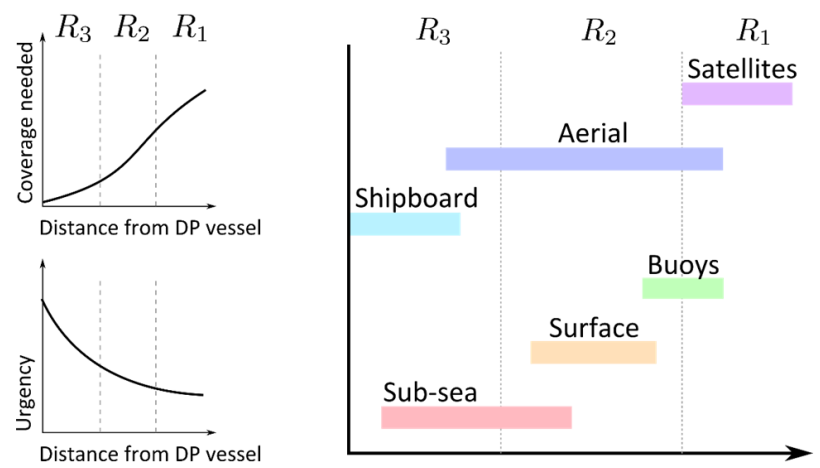

Figure 17: Illustration of coverage achieved by different sensor platforms. $R_{1}$ to $R_{3}$ are ice observation regions of interest, ranked largest to smallest area. Courtesy: Joakim Haugen

The main focus of the RPAS research in this project, was design of path planning algorithms that autonomously guide a number of UAVs to maximize (in some sense) the information content obtained from the sensor network. This is done in a nonlinear programming framework, where the information content in the form of uncertainty reduction is quantified in an objective function to be optimized. The optimization must account for the dynamic maneuverability constraints of the UAVs and other constraints such as anti-collision, cf. Figure 18.

Ice threats in Arctic regions comes in different forms. We found it natural to divide the attention of the ice observation activity along two lines: Surveillance of icebergs, which has strong similarities to what is sometimes termed "target tracking", and monitoring of sea- 


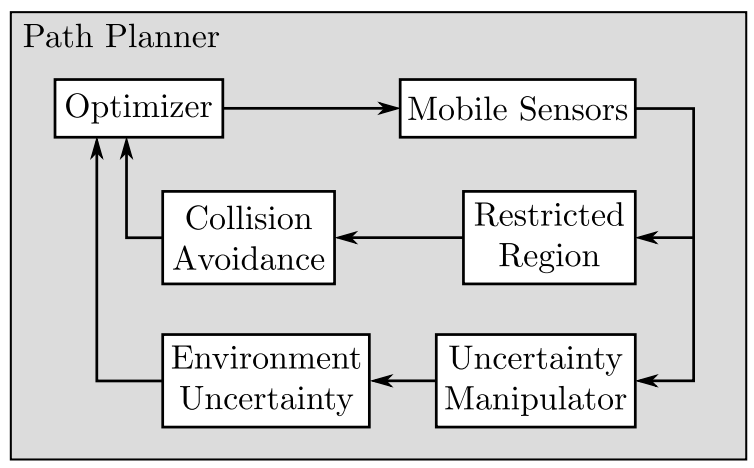

Figure 18: Block diagram for an optimization-based path planner for reducing uncertainty of (ice) environment while avoiding collisions. Courtesy: Joakim Haugen

ice. The latter could be termed "(dynamic) coverage control", where dynamic allude to the drifting nature of sea-ice. Results towards iceberg surveillance, including experiments, can be found in (Haugen and Imsland, 2013a,b, 2014c), while approaches towards surveillance of ice drift can be found in (Haugen et al., 2012; Haugen and Imsland, 2014b). These forms the basis for Joakim Haugen's PhD thesis (Haugen, 2014), which is in part summarized in Haugen and Imsland (2014a).

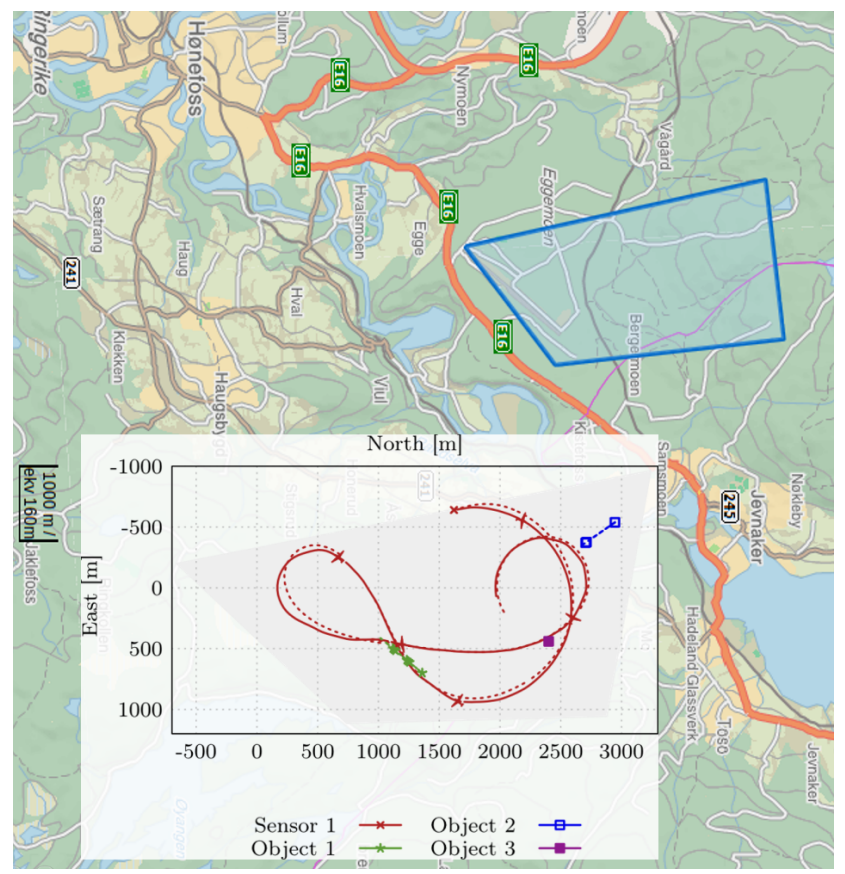

Figure 19: Map over experiment region, in an experiment with one mobile sensor and three "objects" to be monitored. Planned (dashed) and actual (solid) paths shown. Courtesy: Joakim Haugen
The experiments related to iceberg monitoring were performed on Eggemoen Aviation and Technology Park with the skillfull help of Maritime Robotics. We used a "hybrid" setup, meaning that the actual targets ("icebergs") to be monitored were simulated in software, while we planned paths for a real UAV. To the best of our knowledge, this was the first time that "Extended Visual Line-of-Sight" (EVLOS) operations were performed in Norway, cf. Figure 19.

Of course, operating UAVs in Arctic areas has some significant challenges, especially related to harsh weather conditions and deployment from ships, but also communication infrastructure. More research, development and experience is needed, and efforts in this direction are being taken in the new UAV-Lab at the Department of Engineering Cybernetics, NTNU, which is one of two main labs financed by the CoE AMOS. At the time of writing this, the five main areas of research at the UAV-Lab are:

- Smart UAV remote sensing payloads - Autonomous detection, classification, and tracking of objects and distributed features (e.g. icebergs and sea-ice).

- UAV payloads for deployment and recovery, e.g. of ground/floating sensor nodes from UAV.

- Multi-vehicle networking - mobile sensor network.

- Fault-tolerant and robust UAV navigation.

- Enabling ship-based UAV operations in remote and harsh conditions.

All of these are all relevant, to a varying extent, for RPAS operations in Arctic regions. More information about UAV-Lab can be found at http://www.ntnu. edu/amos/uav-lab.

\subsubsection{Sea-ice image processing}

Image processing of visual sea-ice images was early decided to be included in the project due to the fact that various cameras are always part of the sensor suite of Arctic missions, e.g. RPAS surveillance missions in Arctic areas, especially around Svalbard. Later it was found in collaboration with the DYPIC project that also ice tank experiments would benefit from such image processing techniques. This resulted in two main directions of ice image processing for identification of ice parameters, one for model-ice images and one for sea-ice images.

The early entrance to the problem considered methods for accurate calculation of ice concentration. An image as in Figure 20 was then considered, for which global and local thresholding methods can be used to calculate the ice concentration. To this end, the image is first converted into a grayscale image, then the histogram for the pixel values is calculated, and a threshold is determined where the pixel values most appro- 


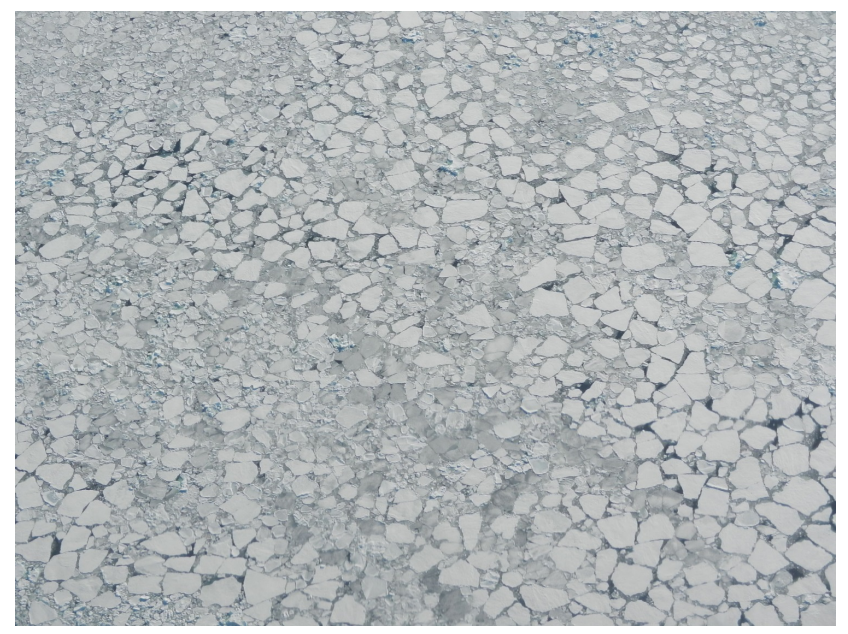

Figure 20: Image of naturally broken sea-ice floes, taken outside Ny-Ålesund May 9, 2011. Photo: Qin Zhang

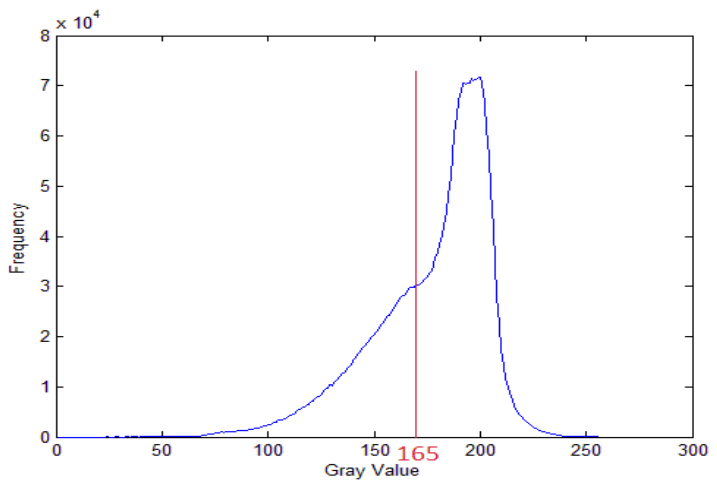

Figure 21: Histogram of the pixel values of the grayscale image, and the chosen threshold (red line) between "ice pixels" and "water pixels". Courtesy: Qin Zhang

priately can be separated into two groups. Pixels with greyscale value below the threshold is then defined as 'water pixels', while those above the threshold is defined as 'ice pixels'. Figure 21 shows this for the seaice image in Figure 20. When nonuniform illumination effects or other local discrepancies exist, then local thresholding is recommended.

High up on the wish list, however, was the ability to automatically calculate the floe size distribution from an image like Figure 20. Conventional methods for boundary detection was then tested with varying result to try to identify individual ice floes. These boundary detection methods had the weakness that they cannot find closed boundaries around individual floes. Some floe boundaries in the image are seemingly connected, that is, the boundary cannot be seen in the image, but we understand it must be there. The existence of the boundary can also be hypothesized from material properties of sea-ice.

Nonetheless, if we can with sufficient accuracy identify the individual ice floes, then we can calculate the position, size, and shape of each individual ice floe, the ice concentration, and the floe size distribution. This have several important application areas as mentioned in (Zhang and Skjetne, 2015; Zhang et al., 2015).

The search for a good image processing algorithm for ice floe identification lead us to the Gradient Vector Flow (GVF) snake algorithm, which can be used to evolve closed curves until they fall at rest at what seemingly are the boundaries of the floes.

The first problem considered was model-ice at HSVA, as reported by Zhang et al. (2012b, 2015) and illustrated in Figure 22. In this special case we had the a priory knowledge that all the ice floes were rectangular. Hence, after our algorithm, based on the GVF snake, had identified the ice floes from the $2 \mathrm{D}$ image, we further employed a rectangularization algorithm to identify the $3 \mathrm{D}$ phenomenon that some ice floes were overlapping, cf. Figure 23.

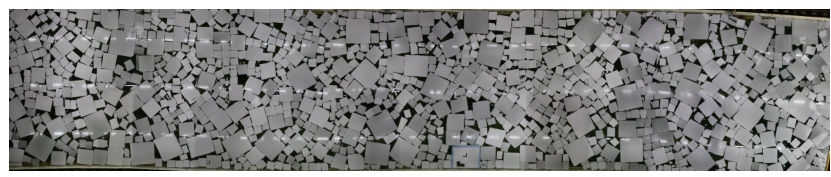

Figure 22: A stitched image of the model-ice at the HSVA ice tank in a case of deterministic ice modeling with square-shaped ice floes. Courtesy: HSVA

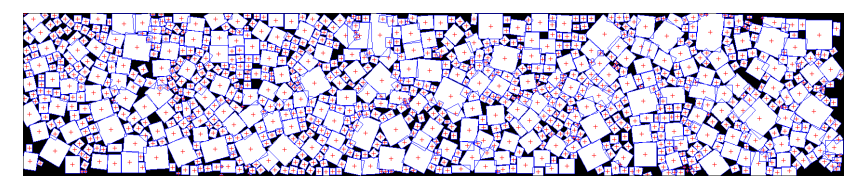

Figure 23: Identified ice floes from the GVF snake algorithm, and further rectangularized to identify overlapping parts between the floes. Courtesy: Zhang et al. (2015)

This was then used to more accuratly calculate the amount of ice in the basin, and better validate numerical models developed based on the ice tank tests; with reference to Figure 7 and the article by Metrikin in this MIC special issue. The corresponding floe size distribution is given in Figure 24 .

For sea-ice images as depicted in Figure 20 there are several other challenges as reported by Zhang and Skjetne (2015), and this has required a slightly different floe identification algorithm. See also (Zhang et al., 


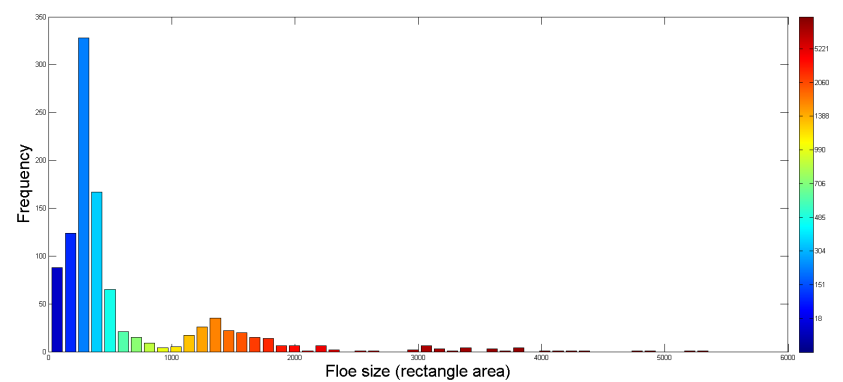

Figure 24: Floe size distribution based on the identified ice floes after the rectangularization process. Courtesy: Zhang et al. (2015)

2012a, 2013). Since also the image is taken at a tilted angle, there is a varying distance from the camera to the ice floes in the image, giving a distortion in the perspective. An orthorectification procedure is therefore needed to compensate for this difference before calculating the floe sizes. After running our algorithm, we get the results shown in figures 25 and 26.

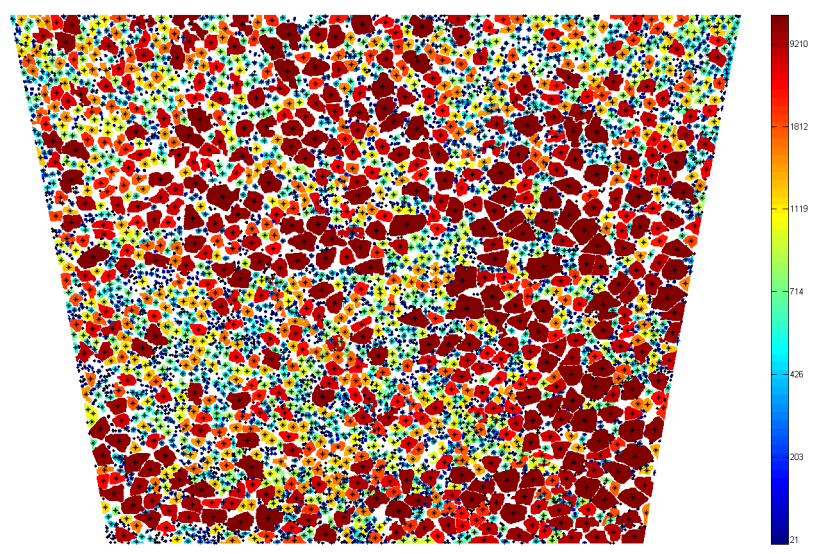

Figure 25: Identified ice floes from Figure 20 based on GVF snake algorithm, with compensation of perspective distortion by orthorectification. Courtesy: Zhang and Skjetne (2015)

The details are given in (Zhang and Skjetne, 2015; Zhang et al., 2015) and Zhang and Skjetne (2014), forming the PhD thesis of Qin Zhang, soon to be defended.

\subsection{Effective control strategies for compensating ice loads}

In addition to effective ship design and ice management, control strategies capable of effectively handling the ice loads with no more than necessary use of the thrusters is necessary for effective dynamic positioning

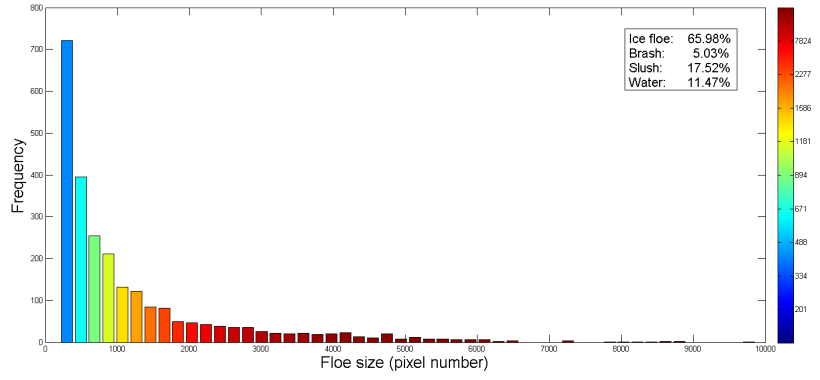

Figure 26: Floe size distribution of sea-ice image. Courtesy: Zhang and Skjetne (2015)

in ice. The first question is then if a reactive control strategy is sufficient or if a proactive control strategy is needed? By a reactive control strategy is here meant a control action implemented as a reaction to load events or disturbances that have occurred. Conventional feedback strategies based on position/heading measurements and feedforward strategies based on measurements of environmental loads fall in this category. A proactive strategy, on the other hand, needs some prediction forward in time such that control action can be implemented as a preventive compensation to load events or disturbances that are about to occur.

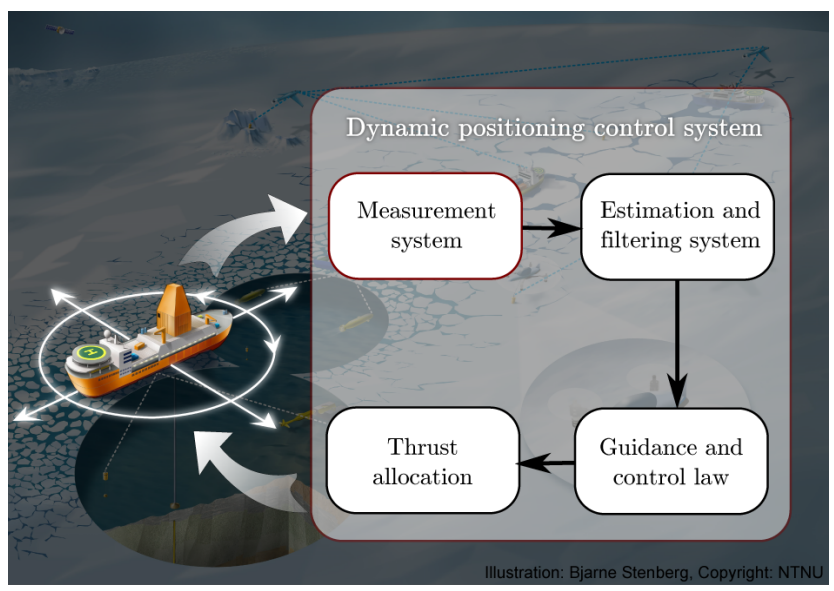

Figure 27: Arctic DP control system modules. Courtesy: Øivind K. Kjerstad

Figure 27 illustrates the typical DP control system modules, also for DP in ice. For an Arctic DP control system, we also consider the Ice Management system as part of the DP system, where icebreakers are used to break and modify the natural ice environment into feasible loads for the DP system to handle. However, as became clear from the ACEX campaign (Moran et al., 2006) and shown in Figure 5, a broken ice field provides formidable loads in high ice concentrations. Methods for handling such loads without degrading system in- 
tegrity and operational safety is therefore a key research topic.

In the Arctic DP project, we have directed the research to the following reactive strategies for ice load compensation:

- Development of an ice characteristics design model that better represent the most important physical phenomena of ice loads on a DP vessel. The goal is then to include this model into the DP observer algorithm with innovation from the conventional DP sensor suite and possibly additional sensors.

- Feedforward compensation of ice loads based on load measurements. Particularly, acceleration measurements from the inertial measurement unit (IMU) is interesting.

Also, a proactive strategy has been considered:

- Feedforward compensation based on an ice load predictive system that are updated by relevant sea-ice parameters provided by an ice surveillance system.

\subsubsection{Reactive control for ice load compensation}

To embark on the difficult task of establishing a better ice load characteristics design model, a study of ice load phenomena was conducted based on experimental data from towing tests and free-floating DP model tests in the DYPIC project at the HSVA ice tank. This study was presented in (Kjerstad et al., 2015) with the following conclusions:

- Global ice loads contain rapid and significant transients that may abruptly inject energy into the stationkeeping system.

- Mean ice loads depend on the oblique angle between the vessel and the ice but not on the relative ice drift velocity (in the range $0.13-0.51 \mathrm{~m} / \mathrm{s}$ fullscale).

- Mean ice loads and standard deviations strongly depend on the ice floe size, ice concentration, and ice thickness.

The study by Kjerstad et al. (2015) showed that the loads from a managed ice field depend strongly on an accumulated ice mass and a developing contact network between the DP vessel and upstream ice floes. This contact network, visualized in Figure 28, can rapidly build up and increase the load. In addition, random events in this contact network may break it down fast, giving a rapid release of force.

In a DP control system, integral action is typically implemented by feedforward from an estimated bias force in the DP observer algorithm (DP Kalman filter, nonlinear passive DP observer, etc.). The degraded performance of conventional open water DP control systems in drifting managed sea-ice conditions, is ob-

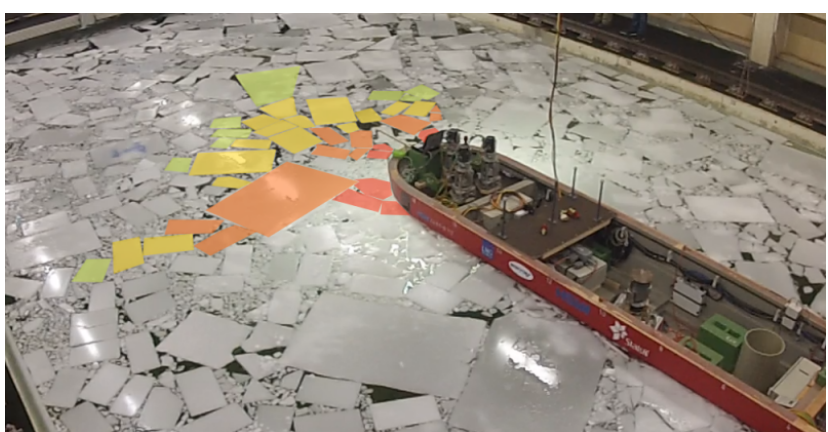

Figure 28: Examples of contact networks forming in the DP experiments at the HSVA testing. Courtesy: Kjerstad et al. (2015)

served to be an inability of the integral action to track the ice loads.

To mitigate this problem, we have studied three reactive control methods:

- Use hybrid resetting mechanisms to update the DP observer bias estimate for more responsive tracking of rapid changes in the external ice loads, based on conventional measurements of position and heading only.

- To update the DP observer also with linear and angular velocity measurements, assuming these are available through some sensor system.

- To update the observer also with 6DOF acceleration measurements.

These methods are all proposed and explored by Øivind K. Kjerstad to form the basis of his PhD thesis. The first proposed method, implementing a hybrid resetting functionality in the DP observer, is work in progress to be published soon. The second method, adding extra velocity measurements, is to some extent presented in Kjerstad and Skjetne (2014).

Using acceleration measurements for disturbance compensation was first presented by Kjerstad et al. (2011), and further results on this is soon to be published. To give the reader a flavor of the idea, consider a mass-damper system

$$
M \ddot{x}+D \dot{x}=u+d(t)
$$

where $(x, \dot{x}, \ddot{x})$ is the position, velocity, and acceleration, $M$ is the inertia matrix, $D$ is a damping matrix, $u$ is the control input, and $d(t)$ is an external load disturbance. Suppose for $d(t) \equiv 0$ that the nominal control law

$$
u=u_{0}=\alpha(t, x, \dot{x})
$$


solves the control objective, giving the closed-loop system

$$
M \ddot{x}=-D \dot{x}+\alpha(t, x, \dot{x})
$$

sufficient performance. For the external load, assume it satisfies a global Lipschitz property, that is, $\exists L \geq 0$ such that

$$
|d(t)-d(\tau)| \leq L|t-\tau|, \quad \forall(t, \tau) \geq 0 .
$$

This essentially means that $t \mapsto d(t)$ is absolutely continuous, and its rate of variation is finite. Ideally, let the acceleration measurement be

$$
a(t)=\ddot{x}(t-\delta)
$$

where $\delta>0$ is a small time delay before the measurement is available in the control law. We now add a feedforward signal $u_{F F}(t)$ to the nominal control law, that is, $u=u_{0}-u_{F F}(t)$, where

$$
u_{F F}(t)=M a(t)+D \dot{x}(t-\delta)-u(t-\delta)
$$

The time delay $\delta$ avoids an algrebraic loop and a causality problem. We get from (7) and (12) that $u_{F F}(t)=d(t-\delta)$, such that the closed-loop system becomes

$$
M \ddot{x}=-D \dot{x}+\alpha(t, x, \dot{x})+d(t)-d(t-\delta) .
$$

From (10) it follows that the effect of the disturbance on the closed-loop system is reduced to $|d(t)-d(t-\delta)| \leq L \delta$, implying that the smaller the time delay $\delta$ is, the smaller the effect of the disturbance becomes. Moreover, slower variation of the signal $d(t)$ makes $L$ smaller, and this will also reduce the effect of the disturbance. In practice the disturbance becomes eliminated given a good acceleration measurement $a(t)$ with high update rate.

We have called this disturbance compensation control mechanism for Acceleration FeedForward (AFF). The dual AFF version for observer design was presented by Kjerstad and Skjetne (2012).

The main challenge with AFF is to provide a good acceleration measurement of the mechanical system. Figure 29 shows an experimental setup on the NTNU research vessel $R / V$ Gunnerus, conducted within the Arctic DP project, where the accelerometers of four noncolocated inertial measurement units are used to estimate both the 3 linear accelerations and the 3 angular accelerations of the vessel. The main finding from this experiment is that it is possible to reconstruct the $6 \mathrm{DOF}$ acceleration vector from four 3-axis accelerometers (Kjerstad, 2014). The details of this will be published later.

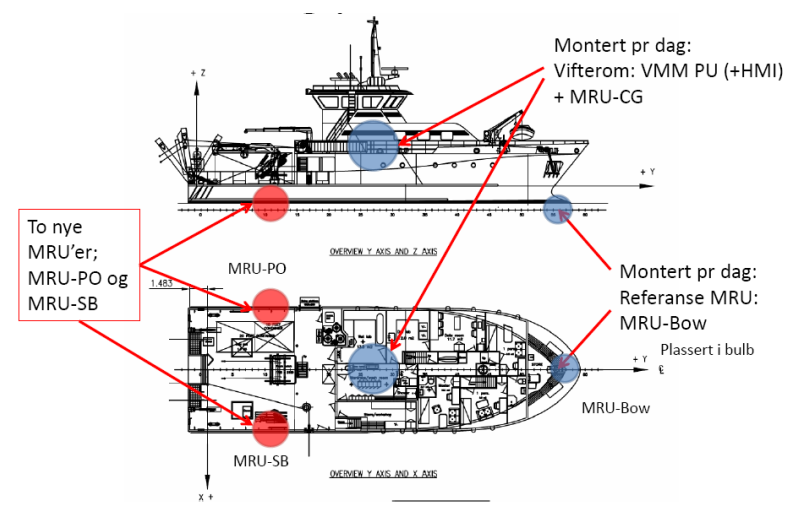

Figure 29: Installation of 4 noncolocated Kongsberg Seatex MRU 5+ inertial sensor units in the NTNU research vessel R/V Gunnerus, for reconstruction of the $6 \mathrm{DOF}$ vessel acceleration. Courtesy: Kongsberg Seatex

\subsubsection{Proactive control for ice load compensation}

Suppose we have available such a sophisticated Ice Surveillance system that we can let the DP control system know in advance what ice loads the vessel will encounter. This will give the ability of the DP control system to plan and guide its motion for optimal handling of ice floe impacts while performing acceptable stationkeeping within its allowed position and heading limits. This generates many interesting ideas:

- By predicting in advance the trends of the encountering ice loads, one can ensure that sufficient thrust is built up to counter the loads when occurring.

- One can guide the DP vessel according to such maneuvers used by the Vidar Viking "drillship" in the ACEX campaign (Moran et al., 2006), where a longitudinal forward and backward motion of $\pm 20 \mathrm{~m}$ relative the drillsite was employed to use the ship's inertia to counter large incoming ice loads.

- By reading the incoming ice force field, one can guide the DP vessel to seek out the path through the ice with lowest loads.

An Arctic DP System block diagram corresponding to such a proactive control strategy is visualized in Figure 30. Clearly some advanced subsystems, such as the IM ILRS, the Ice Surveillance system, and the Supervisory System, need to be well-designd and qualified for such a system to be realized.

With limited resources in the Arctic DP project, we have prioritized some pieces that could go into such a proactive DP system, such as the targeted ice surveillance research tasks. Another prioritized research task, 


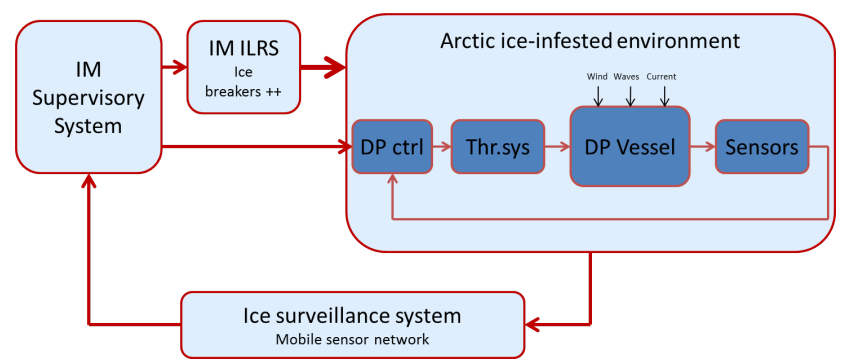

Figure 30: A DP system is placed in an Arctic iceinfested environment. The Ice Management (IM) Ice Load Reduction System (ILRS) use icebreakers as actuation devices to manage the ice environment and reduce the ice loads. An ice surveillance system monitors and estimates necessary ice parameters. A supervisory DP control system acts on the extended ice information and commands the DP vessel and icebreakers to optimize the Arctic DP performance.

applicable for this use, is the development of highfidelity numerical ice-ship simulators. If properly initialized by ice surveillance measurements, such a simulator can be used to predict the future load variations for the vessel and enable ice load compensation by feedforward.

We will end this paper by a presentation of the development of the numerical ice tank simulator developed as a collaboration between the Arctic DP and the DYPIC projects.

\section{Numerical simulation of floating structures in ice}

Due to the limitations in mooring line and/or dynamic positioning capability, ice management that produces broken ice fields is indispensable for a floating structure concept in the Arctic. Global warming is also leading to a thinning of the ice cover allowing gravity waves to penetrate deeper into the Arctic and thus causing broken ice fields being discontinuous in nature, that is, they are composed of distinct ice pieces.

The Arctic DP project has developed a mathematical framework for simulating an offshore structure in a discontinuous ice field, which is composed of discrete elements representing distinct ice floes. The framework is based on the nonsmooth formulation of the Discrete Element Method (DEM). In this formulation, the contacts between discrete elements are treated as visco-elastic unilateral constraints with energy dissipation through impacts and friction. The system of con- straints is formulated as a mathematical optimization problem (linear complementarity problem) and solved iteratively at every timestep.

The numerical model is applicable to the simulation of stationkeeping operations of Arctic drillships and other offshore structures in broken ice conditions, or for modelling ice management operations and concepts.

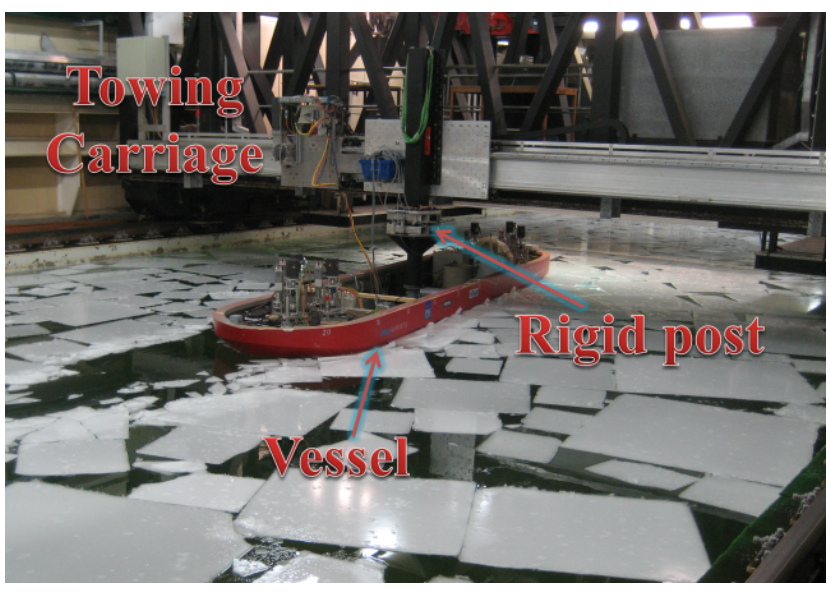

Figure 31: Towing experiment for the Arctic drillship at HSVA.

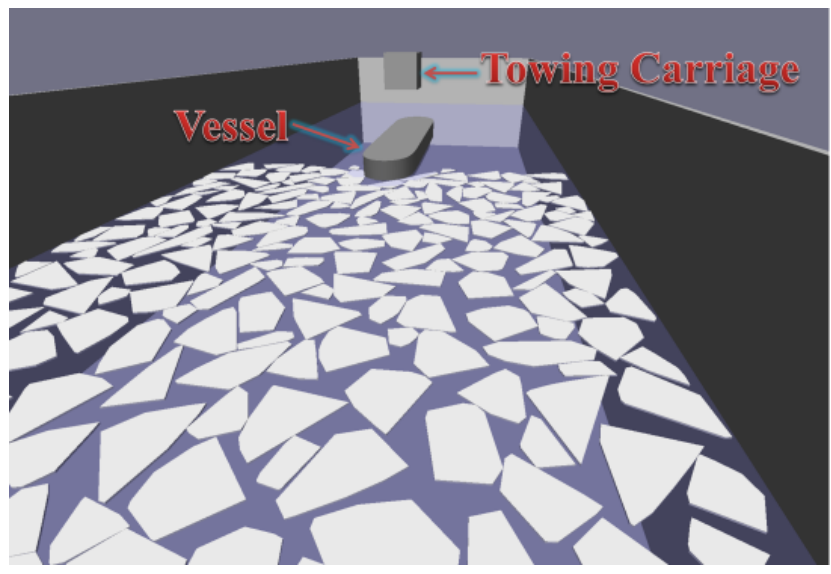

Figure 32: Simulated towing experiment by the numerical ice tank model for the Arctic drillship at HSVA.

The numerical model is then validated against experimental data obtained at the HSVA ice tank by towing a model-scale drillship through a managed ice field (Metrikin and Løset, 2013), as shown in Figure 31. The non-smooth DEM is then used to simulate a model test conducted at HSVA in May 2011 within the framework of the DYPIC project (Jenssen et al., 2012). The model test involved towing a model-scale drillship through a discontinuous ice field while measuring the ice loads 
exerted on it. Figure 32 shows the setup according to the simulator visualization. The ice floes are simulated as rigid bodies in $6 \mathrm{DOF}$. Each ice floe has its own geometrical shape, mass, and inertia tensor. The model concept has been successfully tested against full-scale data with good agreements.

The reader is referred to the article Metrikin (2014), in this MIC special issue on Arctic DP, for details on the numerical model.

\section{Conclusion}

In this article we have described the background for, establishment of, research and development work, and closure of the Arctic DP research project, which was funded by the Norwegian Research Counvil and partners Kongsberg Maritime, DNV GL, and Statoil.

The research activities and results have been focused on some topics under the theme of effective stationkeeping operations in ice.

One focus area has been research on effective ship design for operation in sea-ice and corresponding development of numerical models for verification of ship design and ship operations, both in level ice and in broken ice fields. PhD candidate Ivan Metrikin and postdoctoral fellow Biao Su have worked in this area.

Another focus area has been on effective ice management operations and, in particular, ice surveillance systems for surveying and monitoring sea-ice and icebergs. PhD candidates Joakim Haugen and Ulrik Jørgensen and post-doctoral fellow Francesco Scibilia have worked on these topics, while $\mathrm{PhD}$ candidate Qin Zhang has worked on corresponding image processing techniques for sea-ice.

The last focus area have been on control and guidance strategies for the DP control system to effectively handle loads from drifting sea-ice, where both reactive and proactive methods have been discussed. PhD candidate Øivind K. Kjerstad have worked on this.

In addition, one researcher, Bo Zhao, has worked on fault-detection in DP systems, while researcher Stian Ruud has worked on verification and examination management of complex systems and operations such as an Arctic DP control system and Arctic offshore operation. Both these researchers have provided articles in this MIC special issue.

This article gives an introductory overview of the Arctic DP project in this MIC Special Edition. The additional articles give in-depth treatments of the various research subjects by the different $\mathrm{PhD}$ students and post-docs. The reader is encouraged to study those articles and their references to get on top of the subjects targeted by our Arctic DP project.

\section{Acknowledgments}

The authors would like to thank the Research Council of Norway for the main financial support of the KMB project Arctic DP through project no. 199567. We would also like to thank our industrial scientific partners and financial and in-kind sponsors, being Kongsberg Maritime, DNV GL, and Statoil. We appreciate in particular the effort by their main contacts and human resources in $\mathrm{R} \& \mathrm{D}$ that have been involved.

The work is mainly financed by RCN project 199567 (KMB Arctic DP), and partly by RCN projects 203471 (SFI SAMCoT) and 223254 (SFF AMOS).

\section{References}

Berg, T. E. Summary report RCN project no. 188913/I40: Construction and intervention vessel for Arctic conditions. Report, MARINTEK, Trondheim, Norway, 2012.

Berg, T. E., Berge, B. O., Hönninen, S., Suojanen, R. A., and Borgen, H. Design considerations for an arctic intervention vessel. In In Proc. OTC Arctic Technology Conf., volume OTC-22078. Offshore Technology Conference, Houston, Texas, USA, 2011. doi:10.4043/22078-MS.

Berntsen, P. I. B. Structural Reliability Based Position Mooring. $\mathrm{PhD}$ thesis, Norwegian Univ. Science \& Technology, Trondheim, Norway, 2008.

Børhaug, E., Pavlov, A., and Pettersen, K. Y. Integral LOS control for path following of underactuated marine surface vessels in the presence of constant ocean currents. In Proc. IEEE Conf. Decision \& Control. pages 4984-4991, 2008. doi:10.1109/CDC.2008.4739352.

Eik, K. J. Ice Management in Arctic Offshore Operations and Field Developments. $\mathrm{PhD}$ thesis, Norwegian Univ. Science \& Technology, Trondheim, Norway, 2010. URL http://www.diva-portal.org/ smash/get/diva2:403006/FULLTEXT02.pdf.

Gautier, D. L., Bird, K. J., Charpentier, R. R., Grantz, A., Houseknecht, D. W., Klett, T. R., Moore, T. E., Pitman, J. K., Schenk, C. J., Schuenemeyer, J. H., Sørensen, K., Tennyson, M. E., Valin, Z. C., and Wandrey, C. J. Assessment of undiscovered oil and gas in the arctic. Science, 2009. 324(5931):11751179. doi:10.1126/science.1169467.

Geology.com. Oil and natural gas resources of the arctic. 2014. URL http://geology.com/articles/ arctic-oil-and-gas. 
Haugen, J. Autonomous Aerial Ice Observation. Ph.D. thesis, Norwegian Univ. Science \& Technology, 2014.

Haugen, J., Grøtli, E. I., and Imsland, L. State Estimation of Ice-Thickness Distribution Using Mobile Sensors. In Proc. IEEE Multi-Conf. Systems and Control. Dubrovnik, Croatia, pages 336-343, 2012. doi:10.1109/CCA.2012.6402649.

Haugen, J. and Imsland, L. Optimization-Based Autonomous Remote Sensing of Surface Objects Using an Unmanned Aerial Vehicle. In Proc. European Control Conf. Zurich, Switzerland, pages 12421249, 2013a. URL http://ieeexplore.ieee.org/ stamp/stamp . jsp?tp=\&arnumber $=6669610$.

Haugen, J. and Imsland, L. UAV Path Planning for Multitarget Tracking with Experiments. In Proc. IFAC Workshop Research, Education and Development Unmanned Aerial Systems. Compiègne, France, pages 316-323, 2013b. doi:10.3182/20131120-3-FR-4045.00061.

Haugen, J. and Imsland, L. Autonomous aerial ice observation for ice defense. Modeling, Identification and Control, 2014a. 35(4):279-291. doi:10.4173/mic.2014.4.5.

Haugen, J. and Imsland, L. Monitoring an advectiondiffusion process using aerial mobile sensors. Unmanned Systems, 2014b. Submitted.

Haugen, J. and Imsland, L. Monitoring moving objects using aerial mobile sensors. IEEE Trans. Ctrl. Sys. Tech., 2014c. Accepted.

Haugen, J., Imsland, L., Løset, S., and Skjetne, R. Ice observer system for ice management operations. In Int. Offshore (Ocean) and Polar Eng. Conf. (ISOPE), volume 21. Maui, Hawaii, 2011.

Jenssen, N. A., Hals, T., Jochmann, P., Haase, A., dal Santo, X., Kerkeni, S., Doucy, O., Gürtner, A., Hetschel, S. S., Moslet, P. O., Metrikin, I., and Løset, S. DYPIC - a multi-national R\&D project on dp technology in ice. In Dynamic Positioning Conf. Marine Tech. Soc., Houston, USA, 2012. URL http://www.dynamic-positioning. com/dp2012/arctic_jochmann.pdf.

Jørgensen, U. and Skjetne, R. Online reconstruction of drifting underwater ice topography: The 2D case. Asian J. of Control, 2015. Accepted for publication.

Keinonen, A., Wells, H., Dunderdale, P., Pilkington, R., Miller, G., and Brovin, A. Dynamic positioning operation in ice, offshore sakhalin, may - june 1999. In Int. Offshore (Ocean) and Polar Eng. Conf.
(ISOPE), volume 1. Int. Soc. Offshore and Polar Eng., pages 683-690, 2000.

Kerkeni, S., Metrikin, I., and Jochmann, P. Capability plots of dynamic positioning in ice. In Proc. Int. Conf. Ocean, Offshore \& Arctic Eng., volume 6. American Soc. Mech. Eng., Nantes, France, 2013. doi:10.1115/OMAE2013-10912.

Kjerstad, K. and Skjetne, R. Modeling and control for dynamic positioned marine vessels in drifting managed sea ice. Modeling, Identification and Control, 2014. 35(4):249-262. doi:10.4173/mic.2014.4.3.

Kjerstad, Ø. K. Identifying and handling managed ice challenges for dynamic positioning control systems development. Presentation at NFA Servomøtet, 2014. URL http://www.nfaplassen.no/ arrangementer/servomotet-2014.

Kjerstad, Ø. K., Metrikin, I., Løset, S., and Skjetne, R. Experimental and phenomenological investigation of dynamic positioning in managed ice. Cold Regions Sci. and Tech., 2015. In review.

Kjerstad, Ø. K. and Skjetne, R. Observer design with disturbance rejection by acceleration feedforward. In Proc. IFAC Symp. Robust Control Design, volume 7. IFAC, Aalborg, Denmark, 2012. URL http://www.ifac-papersonline. net/Detailed/53407.html, doi:10.3182/201206203-DK-2025.00157.

Kjerstad, Ø. K., Skjetne, R., and Berge, B. O. Constrained nullspace-based thrust allocation for heading prioritized stationkeeping of offshore vessels in ice. In Proc. Int. Conf. Port Ocean Eng. Arctic Conditions. Espoo, Finland, 2013.

Kjerstad, Ø. K., Skjetne, R., and Jenssen, N. A. Disturbance rejection in dynamic systems by use of acceleration feedforward: Application to dynamic positioning. In Proc. IFAC World Congress Automatic Control, volume 18. IFAC, Milano, Italy, 2011. doi:10.3182/20110828-6-IT-1002.03454.

Metrikin, I. A software framework for simulating stationkeeping of a vessel in discontinuous ice. Modeling, Identification and Control, 2014. 35(4):211-248. doi:10.4173/mic.2014.4.2.

Metrikin, I., Kerkeni, S., Jochmann, P., and Løset, S. Experimental and numerical investigation of dynamic positioning in level ice. In Proc. Int. Conf. Ocean, Offshore \& Arctic Eng., volume 6. American Soc. Mech. Eng., Nantes, France, 2013. doi:10.1115/OMAE2013-10910. 
Metrikin, I. and Løset, S. Nonsmooth 3d discrete element simulation of a drillship in discontinuous ice. In Proc. Int. Conf. Port Ocean Eng. Arctic Conditions, volume 22. Espoo, Finland, 2013. URL http: //www . poac.com/Papers/2013/pdf/POAC13_051.pdf.

Moran, K., Backman, J., and Farrell, J. W. Deepwater drilling in the Arctic Oceans permanent sea ice. Proc. Integrated Ocean Drilling Program, 2006. 302. doi:10.2204/iodp.proc.302.106.2006.

Norsk Forening for Automatisering. Servomøtet. Norwegian Soc. Automatic Control, Kongsberg, Norway, 2014. URL http://www.nfaplassen. no/arrangementer/servomotet-2014. Visited 06.12.2014.

Orsten, A. Automatic Reliability-based Control of Iceberg Towing in Open Waters. MSc thesis, Norwegian Univ. Science \& Technology, Trondheim, Norway, 2014. URL http://www.diva-portal.org/smash/ record. jsf?dswid=-5115\&pid=diva2\%3A746614.

Orsten, A., Norgren, P., and Skjetne, R. LOS guidance for towing an iceberg along a straight-line path. In Proc. IAHR Int. Symp. on Ice. IAHR, Singapore, 2014.

Skjetne, R. and Kjerstad, Ø. K. Recursive nullspacebased control allocation with strict prioritization for marine craft. In Proc. IFAC Conf. Contr. Appl. Marine Systems, volume 9. IFAC, Osaka, Japan, pages 49-54, 2013. doi:10.3182/20130918-4JP-3022.00052.

Su, B., Kjerstad, Ø. K., Skjetne, R., and Berg, T. E. Ice-going capability assessment and DP-Ice Capability Plot for a double acting intervention vessel in level ice. In Proc. Int. Conf. Port Ocean Eng. Arctic Conditions. Espoo, Finland, 2013.

$\mathrm{Su}$, B., Skjetne, R., and Berg, T. E. Numerical assessment of a double-acting offshore vessel's performance in level ice with experimental comparison.
Cold Regions Sci. and Tech., 2014. 106-107(0):96109. doi:10.1016/j.coldregions.2014.06.012.

Sundland, M. N. Guidance and control of iceberg towing operation in open water, with experimental testing. MSc thesis, Norwegian Univ. Science \& Technology, Trondheim, Norway, 2013. URL http://www.diva-portal.org/smash/ record. jsf?pid=diva2\%3A648691\&dswid=-5115.

Zhang, Q. and Skjetne, R. Image techniques for identifying sea-ice parameters. Modeling, Identification and Control, 2014. 35(4):293-300. doi:10.4173/mic.2014.4.6.

Zhang, Q. and Skjetne, R. Image processing for identification of sea-ice floes and the floe size distributions. IEEE Trans. Geoscience Remote Sensing, 2015. 54. doi:10.1109/TGRS.2014.2366640.

Zhang, Q., Skjetne, R., Løset, S., and Marchenko, A. Digital image processing for sea ice observations in support to arctic dp operations. In Proc. Int. Conf. Ocean, Offshore \& Arctic Eng., volume 31. American Soc. Mech. Eng., Rio de Janeiro, Brazil, 2012a. doi:10.1115/OMAE2012-83860.

Zhang, Q., Skjetne, R., Metrikin, I., and Løset, S. Image processing for ice floe analyses in broken-ice model testing. Cold Regions Sci. and Tech., 2015. Accepted.

Zhang, Q., Skjetne, R., and Su, B. Automatic image segmentation for boundary detection of apparently connected sea-ice floes. In Proc. Int. Conf. Port Ocean Eng. Arctic Conditions. Espoo, Finland, 2013.

Zhang, Q., van der Werff, S., Metrikin, I., Løset, S., and Skjetne, R. Image processing for the analysis of an evolving broken-ice field in model testing. In Proc. Int. Conf. Ocean, Offshore \& Arctic Eng., volume 31. American Soc. Mech. Eng., Rio de Janeiro, Brazil, 2012b. doi:10.1115/OMAE2012-84117. 